\title{
Slow GABA Transient and Receptor Desensitization Shape Synaptic Responses Evoked by Hippocampal Neurogliaform Cells
}

\author{
Theofanis Karayannis, ${ }^{1 *}$ David Elfant, ${ }^{1 \star}$ Icnelia Huerta-Ocampo, ${ }^{1}$ Sundeep Teki, ${ }^{1}$ Ricardo S. Scott, ${ }^{2}$ Dmitri A. Rusakov, ${ }^{2}$ \\ Mathew V. Jones, ${ }^{3}$ and Marco Capogna ${ }^{1}$ \\ ${ }^{1}$ Medical Research Council Anatomical Neuropharmacology Unit, Mansfield Road, Oxford OX1 3TH, United Kingdom, ${ }^{2}$ Institute of Neurology, University \\ College London, Queen Square, London WC1N 3BG, United Kingdom, and ${ }^{3}$ Department of Physiology, University of Wisconsin-Madison, Madison, \\ Wisconsin 53706-1510
}

The kinetics of GABAergic synaptic currents can vary by an order of magnitude depending on the cell type. The neurogliaform cell (NGFC) has recently been identified as a key generator of slow $\mathrm{GABA}_{\mathrm{A}}$ receptor-mediated volume transmission in the isocortex. However, the mechanisms underlying slow $\mathrm{GABA}_{\mathrm{A}}$ receptor-mediated IPSCs and their use-dependent plasticity remain unknown. Here, we provide experimental and modeling data showing that hippocampal NGFCs generate an unusually prolonged (tens of milliseconds) but lowconcentration (micromolar range) GABA transient, which is responsible for the slow response kinetics and which leads to a robust desensitization of postsynaptic $\mathrm{GABA}_{\mathrm{A}}$ receptors. This strongly contributes to the use-dependent synaptic depression elicited by various patterns of NGFC activity including the one detected during theta network oscillations in vivo. Synaptic depression mediated by NGFCs is likely to play an important modulatory role in the feedforward inhibition of CA1 pyramidal cells provided by the entorhinal cortex.

\section{Introduction}

In the CNS, phasic IPSCs exhibit various kinetics (Hájos and Mody, 1997; Ouardouz and Lacaille, 1997; Maccaferri et al., 2000; Farrant and Nusser, 2005). They can have a rise time of $<1 \mathrm{~ms}$ and a decay time constant of $<10 \mathrm{~ms}$ (fast IPSCs) (Bartos et al., 2001), but also a rise time of several milliseconds and a decay time constant of tens of milliseconds (slow IPSCs) (Pearce, 1993; Banks et al., 1998). Detailed information on the specific synapses showing distinct responses has only recently started to emerge (Gupta et al., 2000; Molnár et al., 2008). In cortical areas, the neurogliaform cell (NGFC) and the ivy cell (Tamás et al., 2003; Price et al., 2005, 2008; Oláh et al., 2007, 2009; Szabadics et al., 2007; Fuentealba et al., 2008) elicit slow IPSCs in postsynaptic neurons.

Properties of NGFC-evoked responses provide clues to the mechanisms underlying their slow kinetics. First, these responses are highly sensitive to the blockade of the GABA transporter, GAT-1 (Banks et al., 2000; Prenosil et al., 2006; Szabadics et al., 2007). Second, GABA released by a single NGFC action potential

Received Nov. 26, 2009; revised May 28, 2010; accepted June 6, 2010.

This work was supported by the Medical Research Council, United Kingdom, and by the Wellcome Trust. We thank Dr. Marco Beato and Thomas Bienvenu for comments on a previous version of this manuscript. Romana Hauer, Ben Micklem, and Dr. Robert Stewart are acknowledged for their technical aid and expertise.

${ }^{*}$ T.K. and D.E. contributed equally to this work.

Correspondence should be addressed to Dr. Marco Capogna, Medical Research Council Anatomical Neuropharmacology Unit, Mansfield Road, 0xford 0X13TH, UK. E-mail: marco.capogna@pharm.ox.ac.uk.

T. Karayannis's present address: Neuroscience Program, Smilow Research Center, New York University School of Medicine, New York, NY 10016.

DOI:10.1523/JNEUROSCI.5883-09.2010

Copyright $\odot 2010$ the authors $\quad 0270-6474 / 10 / 309898-12 \$ 15.00 / 0$ activates not only $\mathrm{GABA}_{\mathrm{A}}$ but also $\mathrm{GABA}_{\mathrm{B}}$ receptors at both postsynaptic and presynaptic sites, with the latter strongly controlling the amount of GABA or glutamate released (Tamás et al., 2003; Price et al., 2005, 2008; Oláh et al., 2009). Both these phenomena together with the activation of extrasynaptic $\mathrm{GABA}_{\mathrm{A}}$ receptors mediating a tonic conductance on nearby cells (Oláh et al., 2009) suggest an unusual spatiotemporal profile of GABA near the activated synapses. In addition, it has recently been proposed that a low peak GABA concentration exists at the synaptic cleft of NGFCs likely because of the unique structural features of their synapses (Szabadics et al., 2007; Oláh et al., 2009). Importantly, several lines of evidence indicate that the slow IPSCs are unlikely to be attributable to dendritic filtering: (1) they have been confirmed by using the voltage jump method (Pearce, 1993), which overcomes the distance-dependent distortion of synaptic currents away from the soma; (2) both the rise time and decay of IPSCs are slow, with the latter being less influenced than the former by inadequate space clamp; (3) slow responses are observed not only from somatic recordings of pyramidal cells (Tamás et al., 2003; Price et al., 2008) but also from NGFCs with short dendrites synaptically coupled to other NGFCs (Price et al., 2005; Oláh et al., 2009); (4) Martinotti cells form synapses on cortical pyramidal cell dendrites at a longer distance from the soma than NGFCs, yet they elicit faster IPSPs than NGFCs (Szabadics et al., 2007).

The aim of this study was to investigate the temporal profile of NGFC-mediated GABA release and its consequences. Our data show that NGFC-IPSCs are mediated by slow, low-peak GABA transients, leading to desensitization of postsynaptic $\mathrm{GABA}_{\mathrm{A}}$ receptors and synaptic depression. We suggest that this phe- 
nomenon underlies the depression of feedforward inhibition of hippocampal CA1 pyramidal neurons observed after theta burst activity of entorhinal cortex.

\section{Materials and Methods}

Acute slice preparation. All procedures involving animals were performed in accordance with the United Kingdom and European Union regulations. Male postnatal day 18-22 Sprague Dawley rats were anesthetized with isoflurane and decapitated, and their brains quickly removed and placed into ice-cold high-magnesium artificial CSF (ACSF) (composition in mM: $85 \mathrm{NaCl}, 25 \mathrm{NaHCO}_{3}, 2.5 \mathrm{KCl}, 1.25 \mathrm{NaH}_{2} \mathrm{PO}_{4}, 0.5 \mathrm{CaCl}_{2}, 7$ $\mathrm{MgCl}_{2}, 10$ glucose, 75 sucrose) saturated with $95 \% \mathrm{O}_{2}, 5 \% \mathrm{CO}_{2}$, at $\mathrm{pH}$ 7.3. Using a vibratome (VT 1000S; Leica Microsystems), horizontal sections (300-350 $\mu \mathrm{m}$; range, from bregma -6.60 to -4.74 ) were cut containing the hippocampus and attached entorhinal cortex. The slices were allowed to recover in recording ACSF (same as above but $130 \mathrm{NaCl}$, $2 \mathrm{CaCl}_{2}, 2 \mathrm{MgCl}_{2}, 0$ sucrose) at room temperature for at least $45 \mathrm{~min}$ before recording. Acute slices were then placed in a recording chamber mounted on the stage of an upright microscope (Axioscope; Zeiss) equipped with immersion differential interference contrast objectives $(40 \times, 60 \times)$ coupled to an infrared camera system (Hamamatsu), superfused at a rate of $1-2 \mathrm{ml} / \mathrm{min}$ with oxygenated recording ACSF, and maintained at a temperature of $33 \pm 1^{\circ} \mathrm{C}$.

Electrophysiological recordings and data analysis. Whole-cell recordings were performed using EPC10/3 or EPC9/2 amplifiers (HEKA). Interneurons with the soma in the stratum lacunosum-moleculare (SLM) were identified based on soma shape and size under infrared video microscopy. Borosilicate patch electrodes were pulled (Zeitz; DMZ Puller) and filled with the following (in $\mathrm{mm}$ ): $88 \mathrm{KCl}, 42 \mathrm{~K}$-gluconate, $10 \mathrm{HEPES}, 10$ $\mathrm{Na}_{2}$-phosphocreatine, $4 \mathrm{Mg}$-ATP, $0.3 \mathrm{Na}-\mathrm{GTP}, \mathrm{pH} 7.3$ with $\mathrm{KOH}$, to increase the driving force for $\mathrm{Cl}^{-}$ions $\left(E_{\mathrm{Cl}}=-11 \mathrm{mV}\right)$ to the extent that the IPSC polarity was inward at the holding potential $\left(V_{\mathrm{h}}\right)$ of $-65 \mathrm{mV}$. When recording in current-clamp mode, cells were patched with electrodes containing the following (except when stated otherwise, in $\mathrm{mM}$ ): $126 \mathrm{~K}$-gluconate, $10 \mathrm{HEPES}, 10 \mathrm{Na}_{2}$-phosphocreatine, $4 \mathrm{KCl}, 4 \mathrm{Mg}$-ATP, $0.3 \mathrm{Na}-\mathrm{GTP}, \mathrm{pH} 7.3$, with $\mathrm{KOH}$; the osmolarity was $270-280 \mathrm{mOsmol}$. Biocytin was added to the intracellular solutions before recording at a final concentration of $0.1-0.5 \%(\mathrm{w} / \mathrm{v})$. Recording electrodes had resistances between 4 and $6 \mathrm{M} \Omega$. Access resistance was always monitored to ensure the stability of recording conditions. Cells were only accepted for analysis if the initial series resistance was $\leq 20 \mathrm{M} \Omega$ and did not change by $>20 \%$ throughout the recording period. The series resistance was compensated on-line by at least $\sim 50 \%$ in voltage-clamp mode to reduce voltage errors. No correction was made for the junction potential between the pipette and the ACSF, and therefore the recorded membrane potential, as calculated post hoc using a junction potential calculator, was 16 and $11 \mathrm{mV}$ more depolarized than the true membrane potential, for $\mathrm{K}$-gluconate and high- $\mathrm{Cl}^{-}$intracellular solution, respectively.

Presynaptic and postsynaptic neurons were voltage clamped at $V_{\mathrm{h}}=$ $-65 \mathrm{mV}$. Action currents were elicited in a presynaptic cell and the corresponding unitary IPSC was recorded in a synaptically coupled postsynaptic neuron or in the presynaptic neuron as an autaptic IPSC. Postsynaptic and autaptic currents were filtered at $3 \mathrm{kHz}$ and recorded with a sampling rate of $5 \mathrm{kHz}$. Spontaneous IPSCs (sIPSCs) were also filtered at $3 \mathrm{kHz}$ and recorded at $V_{\mathrm{h}}=-65 \mathrm{mV}$ with a sampling rate of 10 $\mathrm{kHz}$ for $120 \mathrm{~s}$. The recorded files were analyzed using Minianalysis software (Synaptosoft), and the peak amplitude, the $20-80 \%$ rise time, and the decay time were calculated by fitting with a single exponential in each trace.

Evoked unitary IPSCs were analyzed off-line using Patchmaster (HEKA) and Igor Pro 5.05 (Wavemetrics). An automated macro was developed in Igor to perform all measurements of synaptic responses including subtraction of traces. Failures were flagged if the IPSCs were smaller than three times the baseline noise (SD of the holding current) or had an onset time that was greater than the average calculated for a file of 30 sweeps plus five times the SD, or when the difference between the onset and the end of the event was $<10 \mathrm{~ms}$. In vivo firing patterns of NGFCs were recorded in anesthetized rats with the juxtacellular/extra- cellular method and analyzed as detailed previously (Fuentealba et al., 2010). One hundred action potentials recorded in NGFCs during theta oscillations were injected into whole-cell patch-clamped cells as voltage pulses (100 mV, 1 ms each) by using Matlab (The MathWorks) and Pulse (HEKA) software. The stimuli evoked a train of action potentials in vitro that exactly matched the sequence of action potentials detected in vivo.

Paired or unpaired Student's $t$ tests, where appropriate, were performed with SPSS or Prism 4.0 (GraphPad Software). When other statistical tests have been used, then they have been specified in the text. Statistical significance was set at $p<0.05$. Values presented in the text and in figures represent the mean \pm SEM, unless otherwise stated.

Two-photon excitation microscopy. Axonal imaging methods used in this study have been detailed previously (Scott and Rusakov, 2006), and the procedures for tracing and identification of NGFC axonal varicosities were described in our previous study (Price et al., 2008). In brief, we used a multiphoton excitation setup comprising a Radiance 2000 imaging system (Zeiss/Bio-Rad) optically linked to a femtosecond laser MaiTai (Newport; SpectraPhysics) and integrated with a single-cell electrophysiology rig. The NGFCs were held in whole-cell mode and loaded with two fluorescent indicators, a morphological tracer Alexa Fluor $594(20 \mu \mathrm{M})$ and $\mathrm{Ca}^{2+}$-sensitive dye (Fluo-4; $200 \mu \mathrm{M}$ ). Fluorophores were excited in two-photon mode at $810 \mathrm{~nm}$, with the laser power optimized for emission detection at different depths in the slice. The axon (which was three to five times thinner than proximal dendrites) was identified and traced using frame scanning mode $(256 \times 256$ pixels, $500 \mathrm{~Hz}$; the number of frames taken was kept small to minimize phototoxic damage) and the system was focused at the maximum optical resolution $(\sim 0.2 \mu \mathrm{m}$; digital capture, $70 \mathrm{~nm}$ per pixel) on varicosities showing, unlike NGFC dendrites, prominent action potential-evoked $\mathrm{Ca}^{2+}$ influx. We started the recording when the resting fluorescence in both Alexa and Fluo- 4 channels was stable ( $\sim 1-2 \mathrm{~h}$ after break-in). Action currents were routinely evoked by $2 \mathrm{~ms}$ somatic command voltage pulses. Fluorescence transients were recorded in linescan mode at $500 \mathrm{~Hz}$ (500 ms sweeps; intersweep inter$\mathrm{val}, 100 \mathrm{~s}$ ) and stored for off-line analysis. The $\mathrm{Ca}^{2+}$-dependent fluorescence response $\Delta F / F$ (integrated over the visible varicosity width) was calculated as $\left(F_{\text {post }}-F_{\text {pre }}\right) /\left(F_{\text {pre }}-F_{0}\right) \cdot F_{\text {pre }}$ and $F_{\text {post }}$ denote the fluorescence (averaged over a sampling time window) before and after stimulation, and $F_{0}$ denotes the background fluorescence measured outside any structure filled with the indicator. The fluorescence signal for each train $(20 \mathrm{~Hz}$ train of four action potentials) was averaged over $200 \mathrm{~ms}$ after the first spike onset. Image analyses were performed on stacks of stored linescan images using a set of custom NIH Image macros. False color tables and averaged images were used for illustration purposes, but the original (gray level) pixel brightness values in each linescan image were used for the quantitative analyses. In most experiments, we reconstructed the axon trajectory using a collage of highresolution Kalman-filtered $z$-stacks 15-20 $\mu$ m deep.

Intracellular labeling and post hoc visualization of recorded cells. After electrophysiological/imaging experiments, slices were immersed for at least $24 \mathrm{~h}$ in fixative (4\% paraformaldehyde, $0.05 \%$ glutaraldehyde, and $0.2 \%$ saturated picric acid in $0.1 \mathrm{~m}$ phosphate buffer, $\mathrm{pH} 7.4$ ). Subsequently, gelatin-embedding and resectioning into $60 \mu \mathrm{m}$ slices was carried out. Recorded cells in the slices were then labeled by avidinbiotinylated horseradish peroxidase complex followed by a peroxidase reaction using diaminobenzidine $(0.05 \%)$ as the chromogen and $\mathrm{H}_{2} \mathrm{O}_{2}$ $(0.01 \%)$ as the substrate. The sections were dehydrated using increasing concentrations of ethanol and permanently mounted on slides. Neurons were drawn $(100 \times$ magnification) using a drawing tube attached to a light microscope.

Electron microscopy. The slices were fixed overnight by immersion in fixative containing $4 \%$ paraformaldehyde, $0.05 \%$ glutaraldehyde, and $15 \%(\mathrm{v} / \mathrm{v})$ saturated picric acid in $0.1 \mathrm{M}$ phosphate buffer, $\mathrm{pH}$ 7.4. The slices were incubated in $1 \% \mathrm{H}_{2} \mathrm{O}_{2}$ to block endogenous peroxidase activity, embedded in gelatin, and resectioned at $60 \mu \mathrm{m}$ thickness. After cryoprotection in $25 \%$ sucrose and $10 \%$ glycerol in $0.1 \mathrm{M} \mathrm{PB}$ overnight, the sections were freeze-thawed in cooled isopentane (BDH Chemicals) and then immersed in liquid nitrogen. Subsequently, the biocytin-filled cells were visualized by the avidin-biotinylated horseradish peroxidise method with diaminobenzidine as a chromogen. All sections were postfixed in $1 \%$ osmium tetroxide (Oxkem) in $0.1 \mathrm{M} \mathrm{PB}$ at $\mathrm{pH} 7.4$ for $\sim 30$ 
min. The sections were then dehydrated through a graded series of dilutions of ethanol with $1 \%$ uranyl acetate included in the $70 \%$ ethanol solution to increase contrast in the electron microscope (EM) and infiltrated with resin overnight (Durcupan; Fluka Chemical). They were then mounted in resin on glass microscope slides and polymerized at $60^{\circ} \mathrm{C}$ for $48 \mathrm{~h}$.

At high magnification, under the light microscope, the soma and dendrites of filled neurons were examined for close appositions with the axon of the parent cell, which in all cases was traced back to the soma. Digital light micrographs were taken at different focal depths from the characteristic axonal and dendritic pattern of the cell and from all appositions before reembedding in Durcupan blocks for ultrathin sectioning. Serial sections of $\sim 70 \mathrm{~nm}$ thickness were collected on Pioloform-coated single slot copper grids, contrasted with lead citrate for $1 \mathrm{~min}$, and examined in a Philips CM 10 EM. All axonal varicosities forming the putative self contacts were followed through several serial sections to establish whether they formed synapses with any other elements. Also, all filled somata were completely serially sectioned for EM analysis to ensure that any inputs, which may have been obscured by the peroxidase labeling at the SLM level, were included in this analysis.

Modeling. We estimated the size and shape of the GABA exposure required to produce slow IPSCs at NGFC synapses by fitting experimentally recorded IPSC waveforms with a previously derived model of $\mathrm{GABA}_{\mathrm{A}}$ receptor kinetics (supplemental Fig. 6, available at www. jneurosci.org as supplemental material). The details of model derivation and validation were published previously (Jones and Westbrook, 1995; Jones et al., 1998). The model was expressed in Q-matrix form (Colquhoun and Hawkes, 1995a,b) and solved numerically with the matrix exponentiation function in Matlab 7 (The MathWorks). The GABA concentration profile was modeled as the biexponential function, $[\mathrm{GABA}](t)=-e^{-\mathrm{t} / \tau \text { rise }}+e^{-\mathrm{t} / \tau \text { decay }}$, scaled to reach a peak concentration $A$. Then, $A$ and the time constants $\tau_{\text {rise }}$ and $\tau_{\text {decay }}$ were allowed to vary as free parameters in minimizing the sum of squared errors between simulated and experimentally recorded currents, using the Nelder-Mead simplex minimization algorithm (Nelder and Mead, 1965). When drugs were used, the model was required to find the single [GABA] profile that simultaneously minimized the error to both the control and drug currents. Because the $[\mathrm{GABA}]$ profile is not known a priori, the fits were constrained to rely solely on relative amplitude (i.e., control vs drug) and shape information, by normalizing all currents and simulations to the peak of the control current in the absence of drug.

Chemicals and drugs. All drugs were applied to the recording preparation through the bath. Salts used in the preparation of the intracellular recording solution and ACSF were obtained from either BDH Laboratory Supplies or Sigma-Aldrich. Kynurenic acid was purchased from Sigma-Aldrich, 6-imino3-(4-methoxyphenyl)-1(6H)-pyridazinebutanoic acid hydrobromide (SR95531), zolpidem, diazepam, (2S)-3-[[(1S)-1-(3,4-dichlorophenyl)ethyl] amino-2-hydroxypropyl] (phenylmethyl)phosphinic acid hydrochloride (CGP55845), GABA, bicuculline, 11,12,13,13a-tetrahydro-7-methoxy-9oxo-9H-imidazo[1,5-a]pyrrolo[2,1-c] [1,4]benzodiazepine-1-carboxylic acid, ethyl ester (L-655708), and (1,2,5,6-tetrahydropyridin-4-yl)methylphosphinic acid (TPMPA) were purchased from Tocris Bioscience.

\section{Results}

Postsynaptic and autaptic responses of hippocampal NGFCs We performed whole-cell patch-clamp recordings in pairs of synaptically connected NGFCs in the presence of antagonists for ionotropic glutamate and $\mathrm{GABA}_{\mathrm{B}}$ receptors (3 $\mathrm{mm}$ kynurenic acid and $5 \mu \mathrm{M}$ CGP55845, respectively). Evoking an action current in the presynaptic NGFC every $120 \mathrm{~s}$ elicited a $\mathrm{GABA}_{\mathrm{A}}$ receptor-mediated current in the postsynaptic NGFC (Fig. 1A1). In $\sim 50 \%$ of cases, this protocol also elicited an inward current in the presynaptic cell occurring shortly after the action current (Fig. 1A2). Both presynaptic and postsynaptic currents were reversibly abolished by the specific $\mathrm{GABA}_{\mathrm{A}}$ receptor antagonist SR95531 (5 $\mu \mathrm{M})$ (Fig. 1 B1,B2). Small currents suggestive of electrical synapses also occurred in synaptically coupled NGFCs (Fig. $1 B 1$ ), as we have previously shown (Price et al., 2005). The syn-

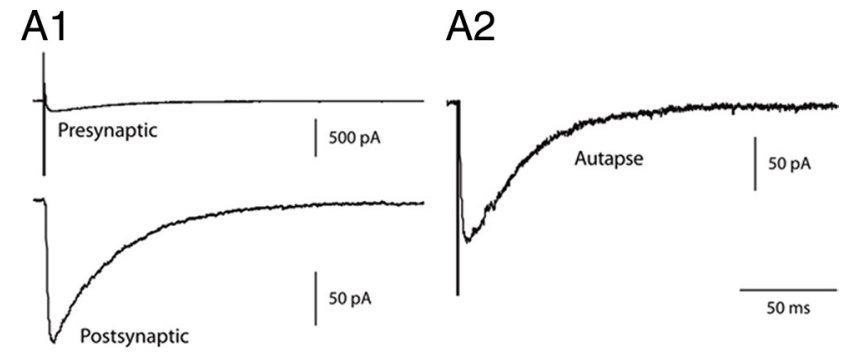

B1 B2
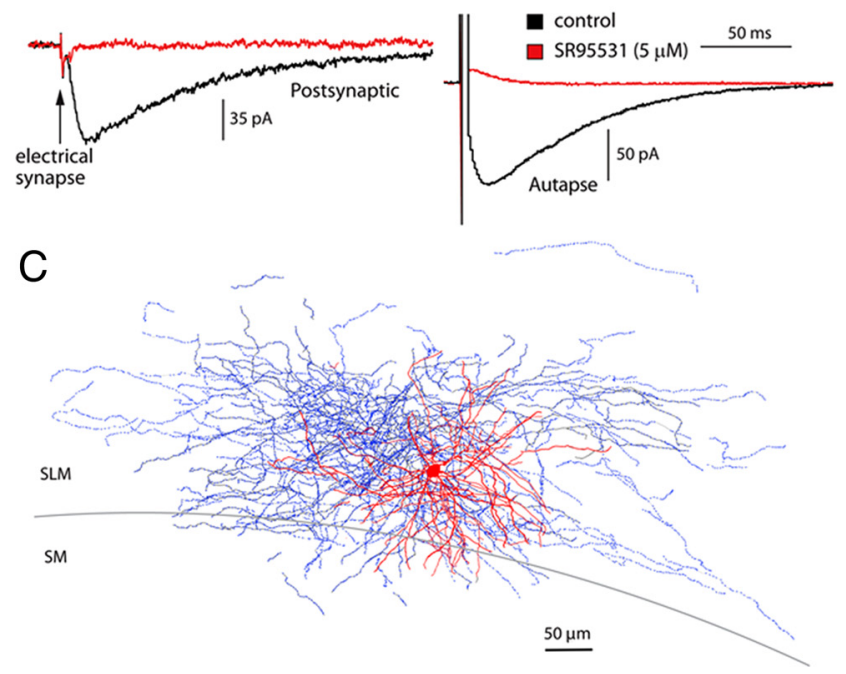

Figure 1. Slow IPSCs recorded from NGFCs. A1, A short square depolarizing voltage pulse applied to a presynaptic NGFC elicited a fast initial action current (top trace), which in turn gave rise to a slow IPSC in a postsynaptic NGFC (bottom trace). A2, Closer inspection of the presynaptic current trace reveals an inward autaptic current after the action current (truncated), which has a similar waveform to the postsynaptic IPSC. $\boldsymbol{B}$, Representative traces showing unitary postsynaptic (B1) and unitary autaptic (B2) IPSCs evoked in NGFCs in control conditions (black) and abolished by the $\mathrm{GABA}_{\mathrm{A}}$ receptor antagonist $\mathrm{SR} 95531$ ( $5 \mu \mathrm{m}$; red). Note that the presynaptic action current that evoked the response shown in $\boldsymbol{B} \mathbf{1}$ is omitted. Note also the presence of a fast transient inward current (arrow) in the traces illustrated in $\mathbf{B} \mathbf{1}$ indicating the presence of an electrical connection in the IPSC. $\boldsymbol{C}$, Light microscopic reconstruction $(100 \times)$ of a biocytinlabeled NGFC (soma and dendrites in red; axon in blue) in acute slice. The axonal arbor remains mostly segregated within the SLM but at some locations crosses the hippocampal fissure into the stratum moleculare. Note also that the axon overlaps extensively with the dendritic arbor forming putative autaptic contacts.

aptic and the autaptic $\mathrm{GABA}_{\mathrm{A}}$ receptor-mediated currents displayed similar amplitudes, rise times, and decay kinetics $(p>$ 0.1 ). On average, the IPSC peak amplitudes were $85.3 \pm 9.6$ and $114.1 \pm 12.5 \mathrm{pA}$, the $20-80 \%$ rise times were $3.69 \pm 0.34$ and $3.39 \pm 0.32 \mathrm{~ms}$, and the fitted decay time constants were $60.3 \pm$ 4.7 and $70.7 \pm 3.5 \mathrm{~ms}$ in postsynaptic $(n=69)$ and autaptic $(n=$ 31 ) currents, respectively. The kinetics of either current match closely those described in the literature as $\mathrm{GABA}_{\mathrm{A} \text {,slow }}$ (Pearce, 1993; Banks et al., 1998, 2000; Tamás et al., 2003; Price et al., 2005, 2008; Prenosil et al., 2006; Oláh et al., 2007, 2009; Szabadics et al., 2007). All cells were filled with biocytin, and only cells identified post hoc as NGFCs were included as such in the study, as detailed previously (Price et al., 2005, 2008); the reconstruction of a representative NGFC is shown in Figure $1 C$. NGFCs were characterized by round somata, short, highly arborizing dendrites close to the soma and an axon that profusely arborized to cover the dendritic tree and stayed most of the times in the SLM, but sometimes crossed to the molecular layer of the dentate gyrus. 

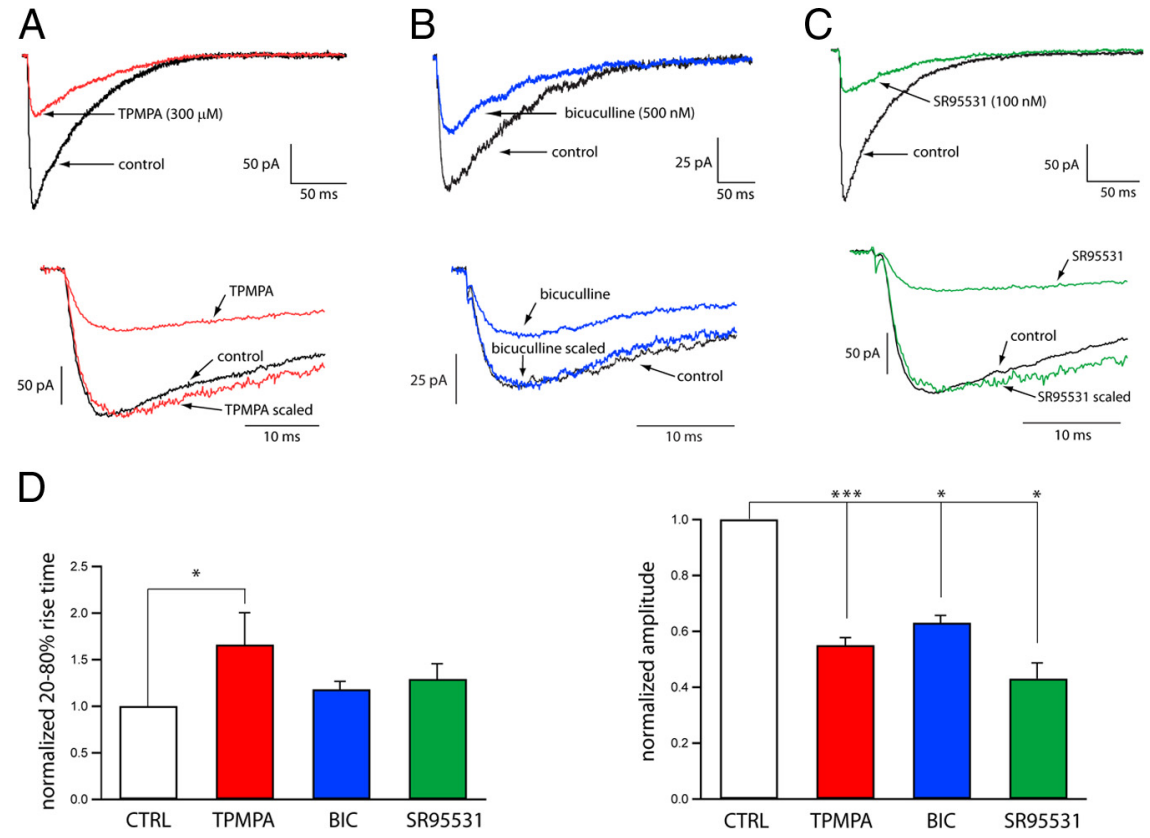

Figure 2. Prolonged duration of GABA after vesicular release at NGFC synapses. $A$, Top traces, Representative traces of NGFCIPSCs showing the effect of $300 \mu \mathrm{M}$ TPMPA (each trace is the average of 5 sweeps). Bottom traces, Closer examination by scaling the attenuated trace to control amplitude reveals that TPMPA prolongs rise time of the IPSC. B, C, Representative traces showing superimposed control and IPSCs during the application of $300 \mathrm{~nm}$ bicuculline or $1 \mu \mathrm{m}$ SR95531 (each trace is the average of 5 sweeps). Scaling of the attenuated trace reveals that neither bicuculline nor SR95331 significantly altered the $20-80 \%$ rise time of the unitary IPSCS. D, Quantification of the actions of TPMPA, bicuculline, or SR95531 on 20-80\% rise time and amplitude of NGFC-IPSCs. Statistical significance is noted $\left({ }^{* * *} p<0.005 ;{ }^{*} p<0.05\right)$. Number of observations were 15 for TPMPA, 5 for bicuculline (BIC), and 6 for SR95331. CTRL, Control. Error bars indicate SEM.

When the NGFCs displaying the autaptic currents were processed and visualized under a light microscope, we could detect, in some but not all cases, close appositions between putative axonal boutons and dendritic elements of the same cell (supplemental Fig. 1A1,B1, available at www.jneurosci.org as supplemental material). Correlated electron microscopic analysis showed that NGFC terminals established membrane-tomembrane appositions without, however, displaying clear-cut synaptic structures (supplemental Fig. 1A2,A3,B2,B3, available at www.jneurosci.org as supplemental material). Moreover, we found that the autaptic currents of the late-spiking NGFCs functionally affected their own firing, as has been previously demonstrated for fast-spiking interneurons (Pawelzik et al., 2003; Bacci and Huguenard, 2006) (supplemental Fig. 2, available at www. jneurosci.org as supplemental material).

These data suggest that hippocampal NGFCs generate postsynaptic and functionally relevant autaptic $\mathrm{GABA}_{\mathrm{A} \text {,slow }}$ responses (NGFC-IPSCs). Since both types of responses displayed similar kinetics and equal sensitivity to the drugs tested (see below), data arising from both have been pooled in the next sections and used to study the mechanism underlying the slow kinetics of NGFC-IPSCs.

\section{Does GABA remain elevated for prolonged periods at NGFC synapses?}

Although GABA released by NGFCs has been shown to diffuse away from the synapse to activate extrasynaptic $\mathrm{GABA}_{\mathrm{A}}$ and $\mathrm{GABA}_{\mathrm{B}}$ receptors, its concentration time dependence is poorly understood (Tamás et al., 2003; Price et al., 2005; Oláh et al., 2009). We therefore first asked whether GABA was present in the synaptic cleft of NGFCs for an unusually long time, thus explaining the slowness of the responses. To test this, we applied com- petitive $\mathrm{GABA}_{\mathrm{A}}$ receptor antagonists at concentrations near their $\mathrm{IC}_{50}$ values, so that receptors reach a dynamic equilibrium with approximately one-half of them bound to the antagonist at any given time. Previous work on fast GABAergic responses predicts that when GABA dwells in the cleft long enough for a $\mathrm{GABA}_{\mathrm{A}}$ receptor antagonist to unbind, then the channels activated after antagonist unbinding will open later than they would have if the antagonist was not present, resulting in longer rise time of the IPSC (Overstreet et al., 2002). We monitored NGFC-IPSCs in control and after the application of TPMPA, an antagonist with low affinity and fast unbinding rate ( $\tau_{\mathrm{u}} \sim 0.6 \mathrm{~ms}$ ) (Jones et al., 2001). As shown in Figure 2, $300 \mu \mathrm{M}$ TPMPA reduced the amplitude from $68.7 \pm 15$ to $31.2 \pm 5.1 \mathrm{pA}(54.6 \pm 4.4 \% ; p<0.005$; $n=15)$, and significantly increased the rise time of the IPSCs from $2.65 \pm 0.54$ to $4.41 \pm 0.98 \mathrm{~ms}$ (Fig. $2 A, D)(p<0.05$; $n=15)$. Surprisingly, the decay time constant of the IPSCs was not significantly affected by TPMPA (112 $\pm 12 \%$ of control; $p>0.1 ; n=15)$, perhaps because of the contrasting influences of the very rapid unbinding rate, and an unusually long duration of the GABA transient at NGFC synapses (see below). The effect of TPMPA was selective for NGFC-IPSCs since this drug did not affect the rise time of fast sIPSCs recorded from NGFCs, but only their amplitude and frequency (supplemental Fig. 3, available at www.jneurosci.org as supplemental material). The amplitude of the fast sIPSC was reduced from $17.2 \pm 1.9$ to $11.8 \pm 1.5 \mathrm{pA}$ $(p<0.05 ; n=6)$, whereas the rise time was unchanged (from $0.52 \pm 0.06$ to $0.53 \pm 0.06 \mathrm{~ms} ; p>0.1 ; n=6$ ). Interestingly, TPMPA reduced the amplitude of NGFC-IPSCs significantly more than that of fast sIPSCs $(p<0.05)$, suggesting a lower concentration of GABA at the former versus the latter synapses, as previously reported in the isocortex (Szabadics et al., 2007). We also tested the effect of the slower unbinding $\mathrm{GABA}_{\mathrm{A}}$ receptor antagonist bicuculline $\left(\tau_{\mathrm{u}} \sim 19 \mathrm{~ms}\right)$ (Jones et al., 2001). Bicuculline (300 nM) significantly reduced the amplitude of the NGFC-IPSCs by $37.1 \pm 5.8 \%(p<0.05 ; n=5)$ but did not change the rise time (from $2.82 \pm 0.82$ to $3.16 \pm$ $1.06 \mathrm{~ms} ; p=0.24 ; n=5$ ) (Fig. $2 B, D)$. Likewise, $100 \mathrm{~nm}$ SR95531, an antagonist with high affinity and slow unbinding rate (Jones et al., 2001), reduced the amplitude of NGFCIPSC by $57.1 \pm 9.6 \%(p<0.05 ; n=6)$ but did not change the rise time from $2.03 \pm 0.63$ to $2.52 \pm 0.71 \mathrm{~ms}(p=0.14 ; n=6)$ (Fig. $2 C, D$ ). These data indicate that GABA remains elevated long enough to cause significant displacement of TPMPA. However, it is difficult to estimate the concentration and duration of GABA from these data alone. Previous estimates of the GABA transient were performed by fitting kinetic models to unitary synaptic events of the "typical low affinity" $\mathrm{GABA}_{\mathrm{A}}$ receptors underlying phasic inhibition, namely benzodiazepine-sensitive, desensitizing receptor containing $\alpha 1 / \alpha 2, \beta 2 /$ $\beta 3$, $\gamma 2$ subunits (Overstreet et al., 2002; Mozrzymas et al., 2003). Thus, before proceeding with kinetic modeling, we aimed to 
further analyze the properties of NGFCIPSCs and the manner of activation of postsynaptic $\mathrm{GABA}_{\mathrm{A}}$ receptors by GABA.

\section{A broad extracellular GABA transient explains $\mathrm{GABA}_{\mathrm{A}}$ receptor activation at hippocampal NGFC synapses}

If there was a diffuse extracellular GABA transient elicited by NGFC firing, then one would expect extrasynaptic GABA transporters to reduce the extent of diffusion, similar to the case of glutamate spillover (Scimemi et al., 2004). Indeed, application of the GAT-1 GABA transporter antagonist SKF89976A (25 $\mu \mathrm{M})$ significantly increased the rise time (from $2.6 \pm 0.6$ to $10.8 \pm 2.9 \mathrm{~ms} ; n=5$ ), the amplitude (from $32.5 \pm 9.6$ to $50.5 \pm 8.2$ $\mathrm{ms} ; n=5$ ), and the decay time constant (from $75.1 \pm 12.4$ to $227.5 \pm 29.9 \mathrm{~ms} ; n=$ 5 ) of the NGFC-IPSCs (Fig. $3 A, C$ ) (all $p<0.05)$. To further test whether this effect was attributable to a relatively longranged extracellular transmitter transient, we reduced release probability by applying $10 \mu \mathrm{M} \mathrm{Cd}^{2+}$. This manipulation should reduce the number of active release sites and therefore enhance, in principle, the independence of postsynaptic receptor sites (Overstreet and Westbrook, 2003). In the presence of $\mathrm{Cd}^{2+}$, the amplitude of NGFC-IPSCs significantly decreased as expected (from $108.3 \pm 21.5$ to $38.4 \pm 6.5 \mathrm{pA} ; p<0.01 ; n=8$ ) (Fig. $3 B, C)$, whereas the rise or decay times were not significantly changed (154 \pm $38 \%, p=0.106$, and $135 \pm 10 \%$ relative to baseline, $p=0.073$, respectively; $n=8$ ). This suggests that activation of few release sites of NGFC axons may already result in a relatively long-range escape of GABA (Szabadics et al., 2007). Likewise, the application of $10 \mu \mathrm{M} \mathrm{Cd}^{2+}$ in the presence of $25 \mu \mathrm{M}$ SKF89976A elicited changes on the rise time and amplitude of the NGFCIPSC that did not reach statistical significance (Fig. $3 B, C)(193 \pm 45 \%, p=0.068$, and $116 \pm 23 \%, p=0.909$, respectively; $n=4)$. Crucially, however, the GABA uptake blocker significantly increased the decay time constant of the IPSCs (from $88.5 \pm 8.7$ to $239.3 \pm 9.3 \mathrm{~ms} ; p<0.005$; $n=4)$. This latter result is in contrast with the evidence that prolongation of unitary fast IPSCs by GABA transport block is severely reduced by experimental manipulations that decrease the number of active release sites (Overstreet and Westbrook, 2003). This disparity indicates that the spatiotemporal profile of GABA released by NGFCs may indeed involve an unusually broad extracellular GABA transient in baseline conditions.

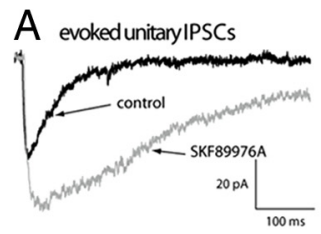

B
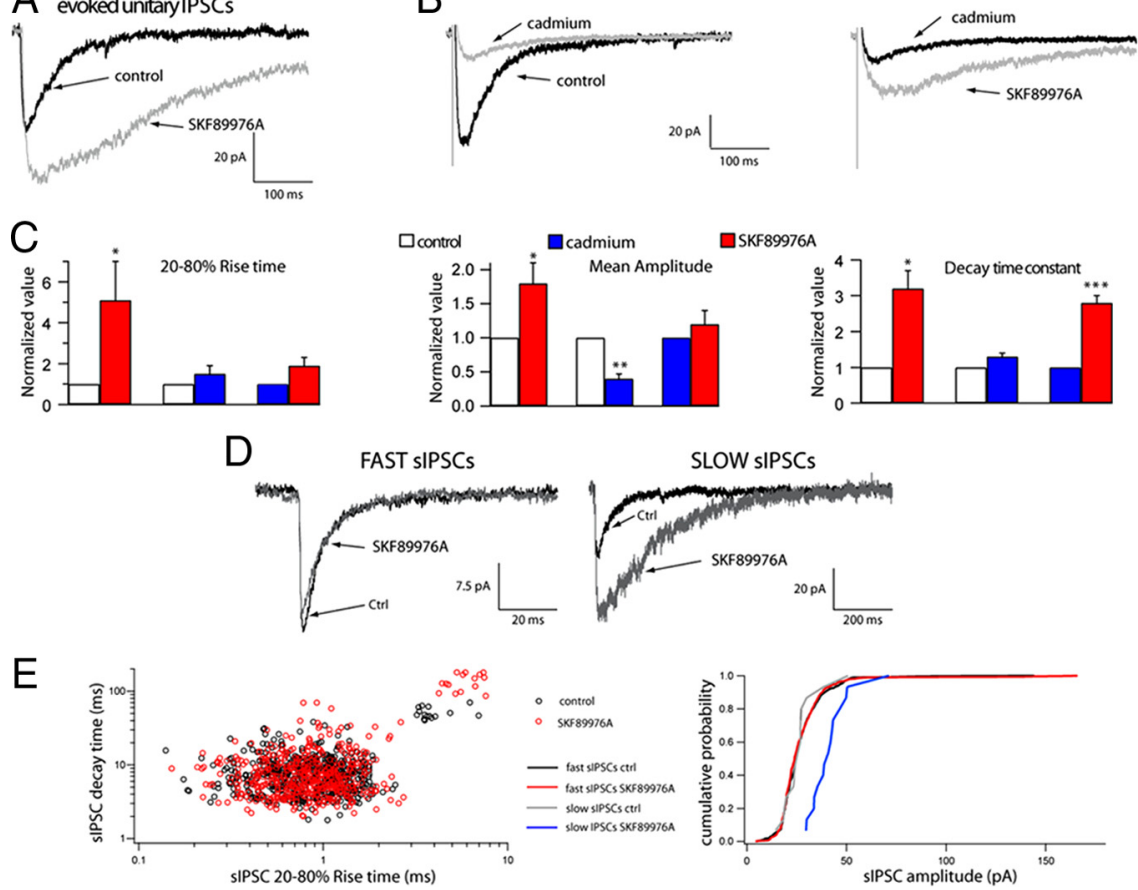

Figure 3. Kinetics of NGFC-IPSCS at low release probability and in the presence of a GAT-1 blocker. $\boldsymbol{A}, \boldsymbol{B}$, Representative traces of NGFC-IPSCs in control or in the presence of $10 \mu \mathrm{M} \mathrm{CdCl}_{2}$ showing the effect of application of $25 \mu \mathrm{m}$ SKF89976A (each trace is an average of 5 sweeps). C, Quantification of the effects of cadmium or SKF89976A on 20-80\% rise time, amplitude, and decay time

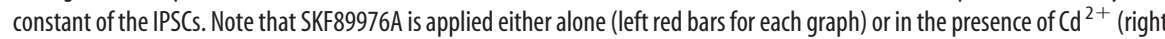
red bars for each graph). Any statistical difference is highlighted with asterisks $\left({ }^{*} p<0.05,{ }^{* *} p<0.01,{ }^{* * *} p<0.005 ; n=5\right.$ for SKF89976A, $n=8$ for $\mathrm{Cd}^{2+}, n=4$ for $\mathrm{Cd}^{2+}$ plus SKF89976A). Error bars indicate SEM. D, Representative examples of fast sIPSCS and slow sIPSCs recorded in NGFCs in control conditions and after application of $25 \mu \mathrm{m}$ SKF89976A. $\boldsymbol{E}$, Quantification of the effect of SKF89976A on sIPSCs. The left graph shows the analysis of 10-90\% rise time (in milliseconds) versus decay time constant (in milliseconds) of 500 sIPSCs recorded from NGFC $(n=5)$. Note the appearance of two populations: a fast rising, fast decaying events (fast sIPSCs), and slowly rising (>3 ms), slowly decaying (>40 ms) events (slow sIPSCs). The two distributions were highly significantly different ( $p<0.001$, Kolmogorov-Smirnov test here and onward). The application of SKF89976A enhanced the rise time and the decay time constant of the slow sIPSCs $(p<0.001)$ but not of the fast sIPSCs $(p>0.1)$. In addition, SKF89976A enhanced the amplitude of the slow SIPSCS $(p<0.001)$ but not of the fast sIPSCS $(p>0.1)$. This latter action is shown in the cumulative plots (right) of the amplitude of fast sIPSCs (number of events, 485) and slow sIPSCs (number of events, 15) in control or during SKF89976A as indicated.
A
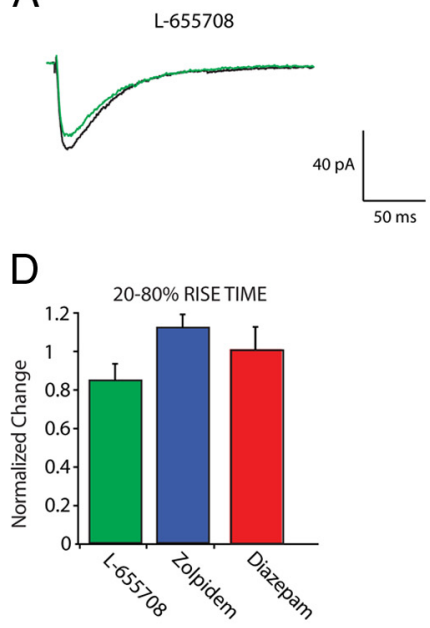

20-80\% RISE TIME
B
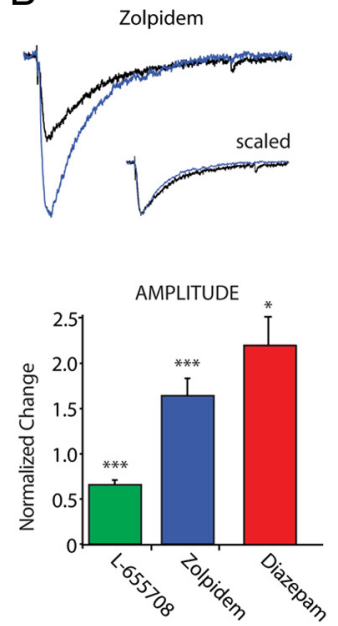

c

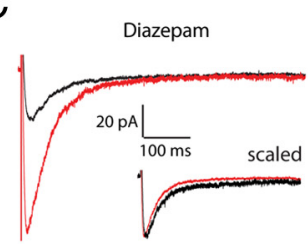

DECAY TME CONSTANT

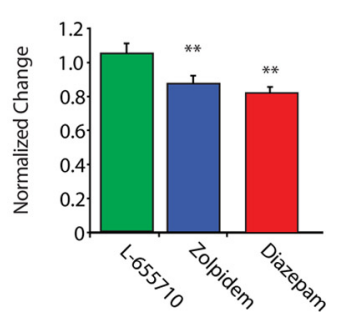

Figure 4. Effects of L-655708, zolpidem, or diazepam on hippocampal NGFC-IPSCs. Representative traces of NGFC-IPSCs in control and after application of $25 \mathrm{~nm}$ L-655708 (A), $100 \mathrm{~nm}$ zolpidem (B), or $1 \mu \mathrm{m}$ diazepam (C). Each trace is the average of five individual sweeps. D, Quantification of the drug effects on $20-80 \%$ rise time, amplitude, and decay time constant of NGFC-IPSCS. Statistical significance is noted where appropriate $\left({ }^{*} p<0.05,{ }^{* *} p<0.01,{ }^{* * *} p<0.005 ; n=6\right.$ for L-655708, $n=17$ for zolpidem, $n=4$ for diazepam). Error bars indicate SEM. 

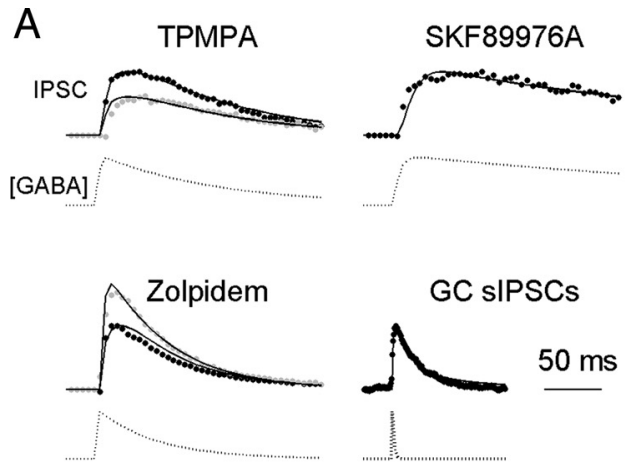

B

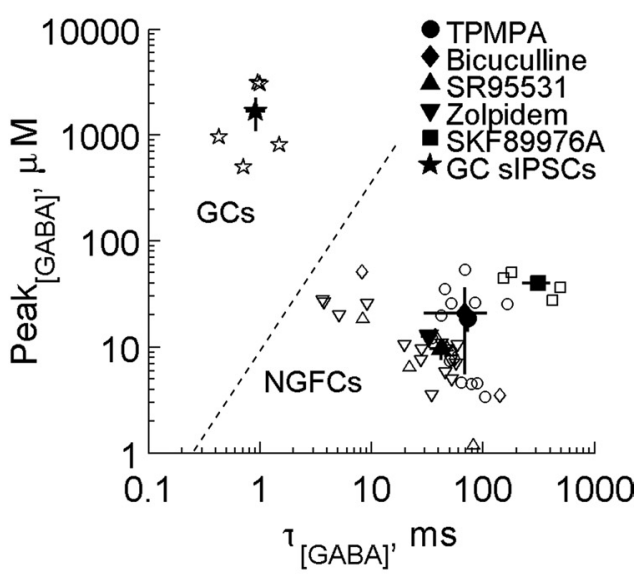

C

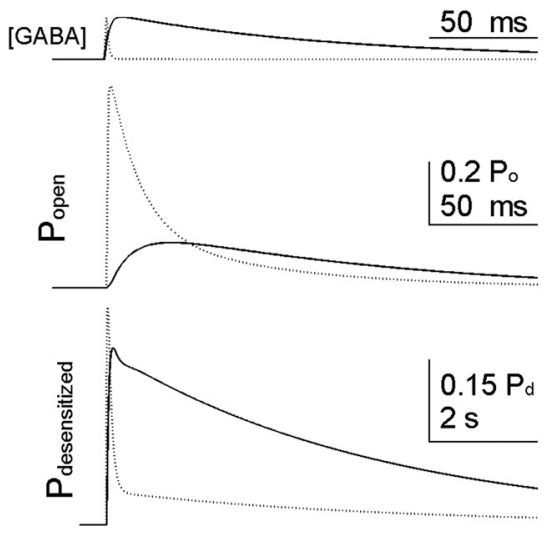

Figure 5. The concentration and duration of GABA that drives NGFC-IPSC. $A$, Experimentally recorded NGFC-IPSCS (dots, normalized to the peak of the control current in each recording) were fit to simulations (solid lines) using the kinetic model shown in supplemental Figure 6 (available at www.jneurosci.org as supplemental material). For each condition, the rate constants of the model were fixed (see supplemental Fig. 6, available at www.jneurosci.org as supplemental material), and only the amplitude, rise, and decay time constants of the synaptic GABA concentration transient (stippled lines, peak normalized for display) were allowed to vary as free parameters. Where $G A B A_{A}$ receptor antagonists or zolpidem were applied, the mode was forced to find the single GABA transient that simultaneously minimized error for both control (black) and drug (gray) conditions. In all cases, NGFC-IPSCs were best fit when the GABA transient was low and long lasting. For comparison, sIPSCs recorded in $\mathrm{GCS}$ of the dentate gyrus were also fit, and required a high but brief GABA transient. $\boldsymbol{B}, A$ plot of the best-fitting peak $G A B A$ concentration versus its decay time constant reveals a clear separation between the concentration profiles underlying fast (GC) and slow NGFC-IPSC, and shows that the latter is driven by GABA exposures of $<100 \mu \mathrm{m}$ that last for tens to hundreds of milliseconds. The dashed line is the boundary that best separates the parameters for NGFCs and GCs, obtained using Fisher's linear discriminant analysis. C, Qualitatively different receptor behaviors are induced by brief and high versus long and low GABA exposure. Simulations using the average GABA concentration transients (top, normalized) for GCs (stippled) and NGFCs (solid) predict
The effect of SKF89976A was specific to the slow IPSCs since this drug did not affect the kinetics of fast IPSCs as analyzed by plotting the rise time versus the decay time constant of spontaneous IPSCs recorded in NGFCs (Banks et al., 1998) (Fig. 3D,E). The application of $25 \mu \mathrm{M}$ SKF89976A significantly shifted the distribution of slow sIPSCs (Kolmogorov-Smirnov test, $p<0.001$; $n=5$ ) toward higher rise time and decay time constant values and also caused a right shift in the cumulative distribution of slow IPSC amplitude (Fig. 3E). In contrast, the drug did not modify the distribution of the kinetic values or the amplitude of fast sIPSCs (Kolmogorov-Smirnov test, $p>0.1 ; n=5$ ) (Fig. $3 E$ ). Importantly, in control conditions, the slow sIPSCs had a mean amplitude of $26.4 \pm 2.3 \mathrm{pA}$, a rise time of $4.1 \pm 0.3 \mathrm{~ms}$, and a decay time constant of $50.9 \pm 2.3 \mathrm{~ms}$. These values were not significantly different from those of evoked NGFC-IPSCs recorded in the same cells ( $p>0.05 ; n=5)$, suggesting that both types of events were likely to be evoked by NGFCs. These data indicate that a broad GABA transient is mainly generated by synapses formed by NGFCs but not interneurons eliciting fast IPSCs (Prenosil et al., 2006). It is noteworthy that prolonging the GABA time course with an uptake blocker prolongs the rise time of slow sIPSCs by several milliseconds. This suggests that the ratelimiting factor in the IPSC rise time is the time of exposure to neurotransmitter, and not the activation kinetics of the underlying $\mathrm{GABA}_{\mathrm{A}}$ receptors (see also below).

\section{The subunit composition of $\mathrm{GABA}_{\mathrm{A}}$ receptors involved in NGFC-IPSC}

The data for NGFC-IPSCs we have provided so far imply that the unique kinetics is generated by an unusual spatiotemporal profile of GABA that activates both synaptic and possibly perisynaptic/ extrasynaptic $\mathrm{GABA}_{\mathrm{A}}$ receptors, which have been shown to be composed by different subunits (Farrant and Nusser, 2005). We tested experimentally this issue by applying specific ligands for $\mathrm{GABA}_{\mathrm{A}}$ receptor subunits on NGFC-IPSCs. First, we tested for the presence of high-affinity GABA receptors, such as $\alpha_{5} \beta_{2 / 3} \gamma_{2}$ receptors, that are thought to be located outside the synapse (Caraiscos et al., 2004) but also at synapses formed by dendritic targeting interneurons (Ali and Thomson, 2008), including cortical NGFCs (Szabadics et al., 2007). Indeed, 25 nM L-655708, an inverse agonist for $\alpha 5$-containing receptors, decreased the amplitude of the NGFC-IPSC (from 92.5 \pm 33.3 to $66.9 \pm 29.4$ pA; $p<$ $0.005 ; n=6$ ) but had no effect on its kinetics (rise time, from $3.9 \pm 0.3$ to $3.2 \pm 0.3 \mathrm{~ms}, p>0.1, n=6$; decay time constant, from $72.9 \pm 13.4$ to $74.9 \pm 11.4 \mathrm{~ms}, p>0.1, n=6$ ) (Fig. $4 A, D)$. In contrast, the drug did not affect fast sIPSCs recorded from NGFCs (rise time, from $0.5 \pm 0.04$ to $0.5 \pm 0.02 \mathrm{~ms}$; decay time constant, from $7.4 \pm 0.7$ to $7.3 \pm 0.9 \mathrm{~ms}$; amplitude, from $16.7 \pm$ 1.2 to $16.4 \pm 0.8 \mathrm{pA}$; for all $p>0.5 ; n=3$ ) (data not shown).

Next, we tested for the presence of the $\alpha 1$ subunit, which is highly and homogenously enriched in NGFC dendrites of the rat hippocampus (Fuentealba et al., 2010). Zolpidem, applied at 100 $\mathrm{nM}$, a concentration specific for synaptic $\alpha 1$-containing receptors, significantly increased the amplitude without affecting the rise time of the NGFC-IPSC (from $140 \pm 22.7$ to $195.9 \pm 28.6 \mathrm{pA}$, $p<0.005, n=17$; from $2.8 \pm 0.3$ to $3.1 \pm 0.3 \mathrm{~ms}, p>0.1, n=17$, respectively) but decreased the decay time constant of the events

that long and low GABA exposure results in lower peak open probability (middle) because of greatly enhanced occupancy of slow desensitized states (bottom). Note the much longer time axis in the bottom plot. 
(from $51.1 \pm 3.9$ to $43.1 \pm 2.9 \mathrm{~ms} ; p<$ $0.01 ; n=17)($ Fig. $4 B, D)$. The latter effect could be partly attributable to enhanced desensitization of $\mathrm{GABA}_{\mathrm{A}}$ receptor by zolpidem (supplemental Fig. 4, available at www.jneurosci.org as supplemental material). In contrast, $100 \mathrm{~nm}$ zolpidem significantly prolonged the decay of fast sIPSCs recorded from NGFCs (from $9.1 \pm 1.4$ to $13.4 \pm 1.2 \mathrm{~ms} ; p<0.05 ; n=$ 5 ), without changing significantly the rise time (from $0.7 \pm 0.2$ to $0.8 \pm 0.3 \mathrm{~ms} ; n=$ 5 ) or the amplitude of the events (from $15.5 \pm 2.6$ to $19.5 \pm 3.0 \mathrm{pA}$; for both $p>$ $0.1 ; n=5)$ (data not shown).

We also tested $1 \mu \mathrm{M}$ diazepam, a positive allosteric modulator of $\mathrm{GABA}_{\mathrm{A}}$ receptors containing either $\alpha 1, \alpha 2, \alpha 3$, or $\alpha 5$ subunits (Wieland et al., 1992). Interestingly, diazepam mimicked the nonclassical action of zolpidem on NGFC-IPSCs, namely a large increase of their amplitude (from $63.2 \pm 17.5$ to $140.1 \pm 39.7$ pA; $p<$ $0.05 ; n=4)$, no significant effect on the rise time (from $3.8 \pm 1.4$ to $3.2 \pm 0.7 \mathrm{~ms}$; $p>0.1 ; n=4)$, accompanied by a significant decrease of the decay time constant of the currents (from 71.2 \pm 5.4 to $55.1 \pm$ $5.1 \mathrm{~ms} ; p<0.05 ; n=4$ ) (Fig. $4 C, D$ ). Similarly to zolpidem, diazepam significantly prolonged the decay of fast sIPSCs recorded from NGFCs (from $6.4 \pm 0.3$ to $10.3 \pm 0.7 \mathrm{~ms} ; p<0.01 ; n=4)$, without altering significantly the rise time (from $0.5 \pm 0.04$ to $0.5 \pm 0.03$ ms; $n=4$ ) or the amplitude of the events (from $14.4 \pm 1.8$ to $17.1 \pm 1.3 \mathrm{pA}$; for both $p>0.1 ; n=4$ ) (data not shown). These results indicate the presence of at least both $\alpha 1$ and $\gamma 2$ subunits in the $\mathrm{GABA}_{\mathrm{A}}$ receptors mediating NGFC responses and a small involvement of the $\alpha 5$ subunit.

Other subunits can substitute for the $\gamma 2$, such as $\delta$ or $\varepsilon$, which would alter the channel response properties. However, the $\varepsilon$ subunit should render the receptors insensitive to zolpidem (Whiting et al., 1997), whereas the extrasynaptic $\delta$-containing receptors, although enriched in isocortical NGFC dendrites (Oláh et al., 2009) do not determine "phasic" NGFC-IPSC (Szabadics et al., 2007). Our results suggest that the differences between synapses formed by NGFCs and other GABAergic cells mainly result not from synapse-specific differences in $\mathrm{GABA}_{\mathrm{A}}$ receptors, but rather from an unusual profile of GABA exposure.

\section{Estimating the concentration and duration of GABA at NGFC synapses}

We therefore asked which waveform of the GABA concentration transient would generate an NGFC-IPSC based on the "typical" $\mathrm{GABA}_{\mathrm{A}}$ receptor kinetics [i.e., those of receptors containing $\alpha 1 / 2$, $\beta 2 / 3$, and $\gamma 2$ subunits, such as those found in granule cells (GCs) of dentate gyrus]. We used a simplex minimization algorithm to optimize the size and shape of the GABA transient to obtain model simulations that best fit the experimental data. Figure 5 shows the results of such estimates. For a physiological range of experimental conditions, NGFC-IPSCs were best fit by a lowconcentration GABA transient that persisted over a long time (Fig. 5A). Although this model does not explicitly account for three-dimensional diffusion of GABA, we validated our semiquantitative conclusions by confirming that very similar predictions were made for experiments with drugs that alter receptor kinetics but do not change the GABA transient, such as competitive antagonists or zolpidem (supplemental Fig. 6, available at www.jneurosci.org as supplemental material). These drugs led to similar estimates of the GABA transient. The estimated peak GABA concentration, rise, and decay time constants were $18.6 \pm$ $4 \mu \mathrm{M}, 3.2 \pm 1 \mathrm{~ms}$, and $73 \pm 10 \mathrm{~ms}$ for TPMPA $(n=12) ; 20 \pm 15 \mu \mathrm{M}$, $0.7 \pm 0.5 \mathrm{~ms}$, and $68 \pm 39 \mathrm{~ms}$ for bicuculline $(n=3) ; 10 \pm 2$ $\mu \mathrm{M}, 1.7 \pm 0.8 \mathrm{~ms}$, and $42 \pm 9 \mathrm{~ms}$ for SR95531 $(n=7)$; and $8 \pm 2$ $\mu \mathrm{M}, 0.4 \pm 0.3 \mathrm{~ms}$, and $35 \pm 3 \mathrm{~ms}$ for zolpidem $(n=12)$. None of these parameters was significantly different between drugs. In contrast, the GABA uptake blocker SKF89976A, which is expected to alter the GABA transient, led to estimates for peak concentration, rise, and decay time constants of $40 \pm 5 \mu \mathrm{M}, 3.8 \pm$ $2 \mathrm{~ms}$, and $312 \pm 85 \mathrm{~ms}(n=4)$, three times larger than in any other condition $(p<0.001)$. For comparison, we used the same method to estimate the GABA transient for sIPSCs at the typical well characterized fast synapses onto GCs of dentate gyrus. At GC synapses, the estimated peak concentration, rise, and decay time constants were $1700 \pm 600 \mu \mathrm{M}, 0.13 \pm 0.01 \mathrm{~ms}$, and $0.9 \pm 0.2 \mathrm{~ms}$ $(n=5)$, similar to a previous study (Overstreet et al., 2002). The peak concentration at fast GC synapses was significantly higher than for all other conditions $(p<0.001)$, and the decay time constant was significantly faster than that estimated for sIPSC in the presence of TPMPA $(p<0.05)$ and SKF89976A $(p<0.001)$. The clear separation in estimated peak and duration of the GABA transient between GC and NGFC synapses is illustrated in Figure $5 B$. 
A

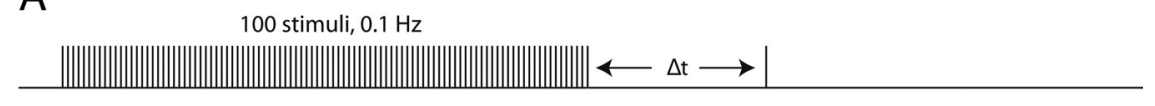

B
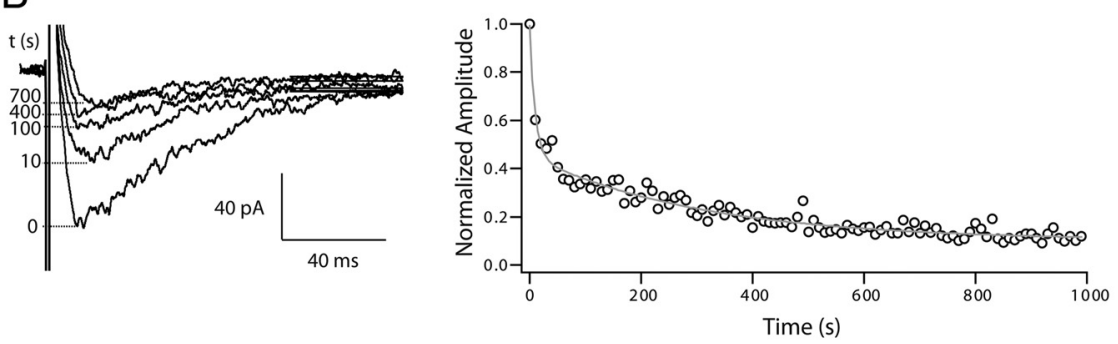

C
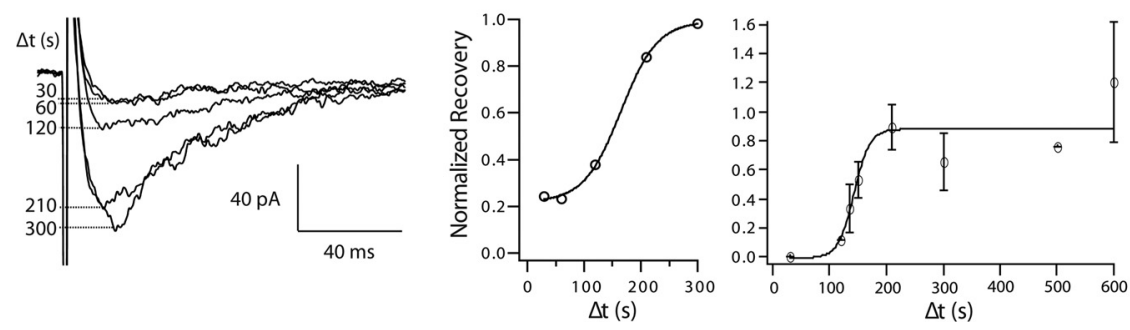

Figure 7. NGFC-IPSCS also depress after low-frequency stimulation. $\boldsymbol{A}$, Stimulation protocol used to study synaptic depression and recovery. Each vertical bar represents a $0.3 \mathrm{~ms}$ depolarizing voltage pulse used to evoke an action current that elicits an autaptic and/or synaptic slow IPSCS. B, Left, Single traces of autaptic NGFC-IPSCs evoked at varying intervals (shown next to each sweep) from the onset of the train. Right, Plot of the normalized amplitude of the IPSC, for the experiment shown, for each stimulus in the train. The data were fitted with a double exponential with a $\tau_{1}$ of $21.9 \mathrm{~s}$ and $\tau_{2}$ of $239.3 \mathrm{~s}$. C, Left, Single traces of NGFC-IPSCs elicited at varying intervals (shown next to each sweep) after a $0.1 \mathrm{~Hz}$ train of stimuli. Right, Summary graph showing percentage recovery from depression at different time points after the train of stimuli for the experiment illustrated (middle graph) and for all data (right graph; $n=26$ ). In the pooled data plot, the recovery from depression had a midpoint of 143.1 s. Error bars indicate SEM.

To ensure that our estimates did not result from biases introduced by our choice of model structure, rate constants, or initial assumptions during fitting, we repeated the fitting procedure for the experiments involving bicuculline, either (1) using a wide range of values for the GABA unbinding rate or the two closing rates, (2) deleting desensitized states altogether, or (3) starting from a large number of random and widely distributed initial assumptions (supplemental Fig. 4, available at www.jneurosci. org as supplemental material). Any of the model conditions chosen were able to generate equally adequate fits, always yielding estimates of a low GABA concentration (1-60 $\mu \mathrm{M})$ lasting for a long time (20-200 ms). Similar estimates were also obtained regardless of the initial guesses during fitting. These results strongly suggest that the kinetics of NGFC-IPSCs arise from an unusually low and slow GABA transient, and do not depend strongly on the kinetics of the postsynaptic receptors.

In addition, these simulations predict that the different profiles of GABA exposure at GC and NGFC synapses lead to qualitatively different receptor behavior. Whereas the brief and high GABA exposure at GC synapses strongly promotes channel opening, the long and low exposure at NGFC synapses preferentially favors desensitization (Fig. $5 C$ ), as suggested by our experimental results and as previously predicted in another study (Overstreet et al., 2002). Although we estimated an average peak GABA concentration of $\sim 30 \mu \mathrm{M}$, the number of receptors activated also depends on the duration of the transmitter transient. Our calculations for the time course of GABA give us a value range of 35-73 ms, which is several times longer than observed at other synapses $(<1 \mathrm{~ms})$. In our model, this transient results in a peak receptor occupancy of $\sim 0.63$, and a peak open probability $\left(P_{\mathrm{O}}\right)$ of $\sim 0.2$. Occupancy drops to $\sim 0.25$ within $500 \mathrm{~ms}$ (i.e., during the decay of the IPSC), as receptors either unbind or enter the slow desensitized state, and thereafter slowly decays to zero over $\sim 15 \mathrm{~s}$, reflecting the slow emptying of slow desensitization $\left(D_{\text {slow }}\right)$ and eventual unbinding of the remainder of receptors. These simulations are consistent with the midterm IPSC depression we observed experimentally in response to multiple stimuli (see below).

Recombinant GABA $_{\mathrm{A}}$ Rs containing $\gamma$ subunits have a single channel conductance $(g)$ of 25-28 pS (Farrant and Nusser, 2005). Since we estimate a peak conductance $(G)$ of NGFC-IPSC of $\sim 3$ $\mathrm{nS}$, the total conductance is $G=N_{\mathrm{C}} g P_{\mathrm{O}}$, and thus the number of channels $\left(N_{\mathrm{C}}\right)$ activated by the NGFC GABA release would be $N_{\mathrm{C}}=G /\left(g P_{\mathrm{O}}\right)=3000 /\left(25^{\star} 0.2\right)=600$ channels. Although there is no information available about how many receptors are present at these synapses, if we assume a value of 50 receptors per synapse, similar to other central inhibitory synapses, then the quantal content would be $m=N_{\mathrm{C}} / 50=$ $600 / 50=12$ vesicles. Unfortunately, the slow stimulation frequency necessitated by the extensive synaptic depression precludes a detailed quantal analysis or variance analysis to accurately estimate the synaptic release probability or number of active sites.

We therefore conclude that, unlike common inhibitory synapses that are driven by a GABA transient that reaches into the millimolar range but decays within a millisecond, NGFC-IPSCs are driven by a low concentration of GABA $(<100 \mu \mathrm{M})$ that persists for a long time (tens of milliseconds) despite being limited by GABA uptake, as this duration is prolonged more than three times when uptake is blocked. This long exposure that favors desensitization could be the underlying reason why previous work reported stimulation of these cells as low as every 2 min to evoke stable synaptic responses (Tamás et al., 2003; Price et al., 2005). Furthermore, this can also be the cause of the reduction of the long-lasting direct CA1 feedforward inhibition from the entorhinal cortex (mediated partly by NGFCs) on repeated theta burst activity of this input even after $\mathrm{GABA}_{\mathrm{B}}$ receptor blockade (Dvorak-Carbone and Schuman, 1999). We therefore addressed this issue by assessing the stimulation frequency-dependent dynamics of NGFC-IPSCs.

\section{Use-dependent synaptic depression mediated by NGFCs}

To assess the role of NGFCs in the theta-burst activity from the entorhinal cortex, we started off by addressing whether NGFC synaptic responses depress if stimulated in vitro the same way NGFCs fire in vivo. We have recently observed that NGFCs fire action potentials differentially phase locked to various rhythmic activities of the hippocampus in vivo (theta, gamma, or ripples) (Fuentealba et al., 2010). Therefore, we injected into in vitro recorded NGFCs in vivo NGFC firing phase-locked to theta oscillations in the absence or in the presence of $\mathrm{GABA}_{\mathrm{B}}$ receptor blockade with $5 \mu \mathrm{M}$ CGP55845 (the two sets of data gave similar results, $p>0.1$, and have therefore been pooled). The NGFC in 
vivo theta phase-locked activity elicited a robust but reversible depression of either autaptic or postsynaptic NGFC-IPSCs (Fig. 6). When the normalized amplitude of the IPSCs was plotted against time, the gradual decrease in amplitude during the train of action potentials could be fitted with a double exponential with a $\tau_{1}$ of $0.3 \mathrm{~s}$ and $\tau_{2}$ of $3.9 \mathrm{~s}(n=9)$ (Fig. $\left.6 B\right)$. However, IPSCs evoked by a single action potential posttrain recovered fully within $\sim 20 \mathrm{~min}$, and the recovery could be fitted with an average time constant of 10.4 min (Fig. 6C). Interestingly, this form of synaptic depression was specific for NGFC synapses, since unitary IPSCs observed in paired recording experiments of other types of interneurons of the SLM (anatomically identified) displayed a very different behavior. The same protocol (or other random in vivo firing activity of hippocampal interneurons) (data not shown) resulted in just a slight depression of the IPSC peak amplitude ( $10 \pm 7 \%$ of control; $n=3$ for the same protocol) at the end of the stimulation (supplemental Fig. 5, available at www.jneurosci.org as supplemental material). Thus, the synaptic depression we report here at NGFC synapses is longer in duration than short-term depression lasting only for a few seconds, but shorter than long-term depression that may last indefinitely, and we hence called it midterm depression.

We also studied NGFC-IPSCs evoked by a train of action potentials at $0.1 \mathrm{~Hz}$ (in the presence of $5 \mu \mathrm{M}$ CGP55845, a GABA receptor antagonist); this low frequency was used to minimize the contribution of presynaptic factors to the depression (Rizzoli and Betz, 2005). Similarly to the in vivo firing pattern-induced depression, this protocol elicited a robust but reversible depression of the NGFC-IPSCs (Fig. 7), but not in other types of interneurons of the SLM (anatomically confirmed) (supplemental Fig. 5, available at www.jneurosci.org as supplemental material). The peak amplitude of NGFC-IPSC at the end of the $0.1 \mathrm{~Hz}$ train stimulation was depressed by $80 \pm 6 \%$ of the first IPSC $(n=12)$, whereas by only $15 \pm 7 \%$ when the presynaptic cell was another type of interneuron $(n=4)$. Interestingly, the application of the GAT-1 blocker SKF89976A (25 $\mu \mathrm{M})$ markedly accelerated and enhanced the depression elicited by $0.1 \mathrm{~Hz}$ stimulation $(p<$ $0.005 ; n=6$; $F$ test) (Fig. $8 A$ ), and a similar result was observed after the application of $1-2 \mu \mathrm{M}$ GABA $(p<0.05 ; n=4 ; F$ test $)$ (Fig. $8 B$ ). In contrast, the competitive fast-dissociating $\mathrm{GABA}_{\mathrm{A}}$ receptor antagonist TPMPA $(300 \mu \mathrm{M})$ slowed and reduced this depression ( $p<0.05 ; n=10 ; F$ test) (Fig. $8 A)$. Finally, we examined NGFC-IPSCs evoked by a pair of presynaptic action potentials separated by varying intervals (Fig. $8 C$ ). We observed a large depression after the first stimulus that recovered with a time constant of $12.9 \mathrm{~s}$ (Fig. $8 C)(n=10)$, consistent with the time constant of recovery from slow desensitization (15.8 s) reported previously (Overstreet et al., 2000). These results together suggest that postsynaptic receptor desensitization is an important mechanism involved in the synaptic depression elicited by $0.1 \mathrm{~Hz}$ stimulation. This is because manipulations that lead to higher GABA concentrations and hence increase the time it stays bound to the receptors (SKF89976A and exogenous GABA) enhanced the depression, whereas TPMPA, which reduces the time GABA stays bound to the receptors, reduced the depression.

\section{The relationship between use-dependent plasticity and presynaptic $\mathrm{Ca}^{2+}$ at NGFC synapses}

Short-term use-dependent synaptic plasticity has been classically associated with changes in presynaptic $\mathrm{Ca}^{2+}$, although usually the frequency of stimulation used is much higher than the $0.1 \mathrm{~Hz}$ stimulation used here (Zucker and Regehr, 2002). To test a potential role of presynaptic $\mathrm{Ca}^{2+}$ in the $0.1 \mathrm{~Hz}$ depression observed
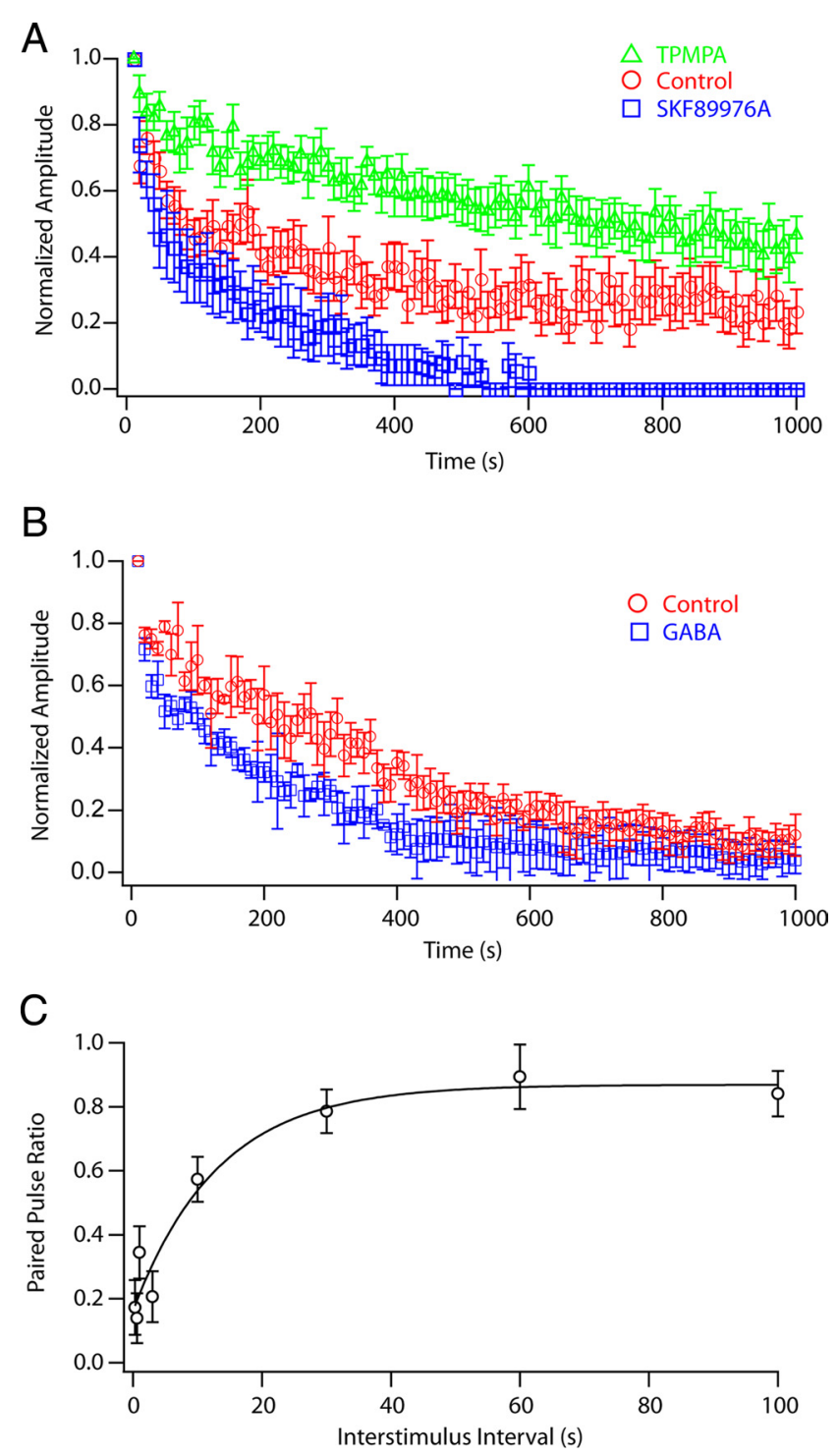

Figure 8. Slow receptor desensitization leads to the depression of low-frequency evoked NGFC-IPSCS. A, A train of 100 depolarizing pulses applied at $0.1 \mathrm{~Hz}$ produced a marked depression in the IPSC $(n=12)$. Increasing the ambient GABA concentration by application of $25 \mu \mathrm{M}$ SKF89976A caused a marked downward shift in the IPSC amplitude versus time relationship $\left(p<0.005 ; n=6\right.$; Ftest). In contrast, the fast-off GABA $A_{A}$ receptor antagonist TPMPA $(300 \mu \mathrm{M})$ elicited a significant upward shift in this relation ( $p<0.005 ; n=10 ; F$ test). $\boldsymbol{B}$, In the presence of 1-2 $\mu \mathrm{m} G A B A$, a similar protocol of $0.1 \mathrm{~Hz}$ stimulation induced a significantly faster synaptic depression than in controls ( $p<0.05 ; n=4 ; F$ test). $C$, Graph showing the recovery from desensitization expressed as change in paired-pulse ratio with increasing interstimulus interval (range, $0.3-100 \mathrm{~s}$ ). The relationship can be described by a single exponential curve that reaches a plateau after $\sim 40 \mathrm{~s}(n=10)$. Error bars indicate SEM.

here, we monitored evoked $\mathrm{Ca}^{2+}$ transients at individual axonal boutons of NGFCs, as detailed previously (Price et al., 2008). We loaded the neurons with the morphological tracer Alexa Fluor 594 and with the $\mathrm{Ca}^{2+}$-sensitive dye Fluo-4 $(200 \mu \mathrm{M})$ for $>1 \mathrm{~h}$, a time when we still observed the synaptic depression, and thus visualized the typical dense axonal plexus of NGFCs (Price et al., 2008). A short train of action potentials (four pulses at $20 \mathrm{~Hz}$ at $0.1 \mathrm{~Hz}$ for $10-20 \mathrm{~min}$, protocol optimized for detection of $\mathrm{Ca}^{2+}$ transients in small axonal boutons of NGFCs) evoked stable presynaptic $\mathrm{Ca}^{2+}$ signals, so that we did not observe significant changes between the $\mathrm{Ca}^{2+}$ transients evoked at the beginning compared with the end (after $1000 \mathrm{~s}$ ) of the protocol (Fig. 9A,B) 
A
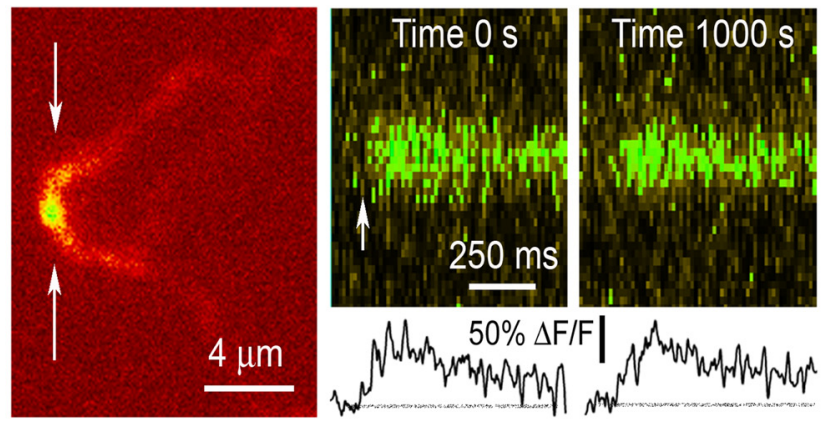

B

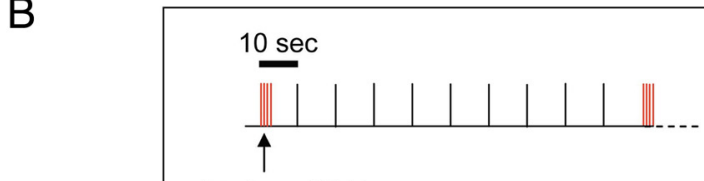

4 pulses, $20 \mathrm{~Hz}$

Line scanning

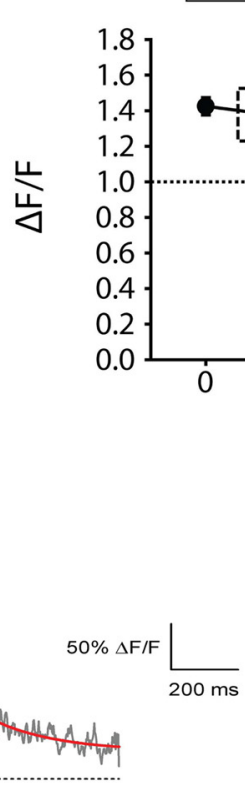

Non-NGFC

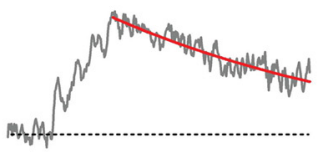

NGFC

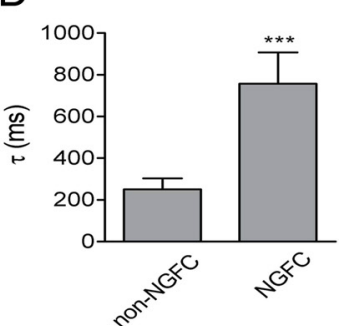

Figure 9. Changes in presynaptic $\mathrm{Ca}^{2+}$ signal do not contribute to the synaptic depression. $\boldsymbol{A}$, Image of an axonal varicosity of a NGFC (left panel) and $\mathrm{Ca}^{2+}$ transients at the beginning (time $0 \mathrm{~s}$ ) and at the end (time $1000 \mathrm{~s}$ ) of the protocol shown in $\boldsymbol{B}$. The morphological tracer Alexa Fluor $594(40 \mu \mathrm{m})$ and the $\mathrm{Ca}^{2+}$ indicator Fluo-4 $(200 \mu \mathrm{m})$ were used. The protocol consisted of intracellular stimulation with four action potentials at $20 \mathrm{~Hz}$ every $10 \mathrm{~s}$ for $\sim 17 \mathrm{~min}$. $\boldsymbol{B}$, The $\mathrm{Ca}^{2+}$ transients detected in axonal boutons of NGFCs by this protocol were stable and no significant changes were observed during $1000 \mathrm{~s}$ of stimulation. The plot shows average values \pm SEM $(n=8)$. C, Fluorescence transients from non-NGFC (left) and NGFC boutons (right) induced by trains of four somatic pulses applied through the whole-cell electrode. Each transient is an average of at least 10 trials. Monoexponential functions were fitted to the decay phase of the transient just after the last pulse of the trains. $D$, Summary of the data for the decay time constant of the fluorescence transients for both types of cells. The $\mathrm{Ca}^{2+}$ signals from NGFCs decay three times slower than in other types of interneurons (data are mean \pm SEM from NGFCs or other interneurons with the soma in the SLM; $n=6$ each; $^{* * *} p<0.001$ ).

( $p>0.5 ; n=8)$. This was not attributable to insufficient sensitivity of the method because the same approach could readily detect small changes in presynaptic $\mathrm{Ca}^{2+}$ in NGFC axonal boutons imaged under different stimulation protocols (Price et al., 2008). Interestingly, presynaptic $\mathrm{Ca}^{2+}$ transients recorded in NGFCs decayed three times slower than presynaptic $\mathrm{Ca}^{2+}$ transients in non-NGFCs interneurons of the SLM $(757 \pm 151$ and $250 \pm 53 \mathrm{~ms}$, respectively; $n=6$ each group; $p<0.001$ ) (Fig. $9 C$ ) or in CA1 interneurons with the soma in the stratum radiatum, as documented previously in similar imaging experiments
(Rusakov et al., 2004). The distinctly slow decay of $\mathrm{Ca}^{2+}$ fluorescence indicates either the slow removal of residual $\mathrm{Ca}^{2+}$ postspike or a relatively low capacity of endogenous $\mathrm{Ca}^{2+}$ buffers present at the presynaptic bouton, or both (Scott and Rusakov, 2006). In summary, these data suggest that the classical mechanism involving progressive reductions in individual spike-evoked presynaptic $\mathrm{Ca}^{2+}$ transients cannot account for the synaptic depression observed. Instead, the prolonged elevation of presynaptic $\mathrm{Ca}^{2+}$ in NGFCs may reflect increased probability of transmitter release events for a period of time after the spike, which might provide an explanation for the long presence of GABA at this synapse.

\section{Discussion}

Our experimental and modeling data suggest that hippocampal NGFCs mediate nonconventional release of GABA into the extracellular space that gives rise to a prolonged, low GABA concentration that determines the slow IPSC kinetics. This unusual GABA profile promotes desensitization of postsynaptic $\mathrm{GABA}_{\mathrm{A}}$ receptors which in turn contributes to synaptic depression occurring during in vitro replayed NGFC in vivo firing patterns or at low frequencies of synaptic activation $(0.1$ $\mathrm{Hz}$ ). Because of its time course, we have called it midterm depression.

The slow inhibitory synaptic responses were first noticed in CA1 pyramidal cells (Pearce, 1993; Banks et al., 1998) and their specific cellular origin later established as NGFCs using paired recordings in isocortex (Tamás et al., 2003; Szabadics et al., 2007) and CA1 hippocampus (Price et al., $2005,2008)$. In the latter structure, interneurons termed ivy cells also generate slow synaptic inhibitory responses in CA1 pyramidal neurons (Fuentealba et al., 2008). We found that a NGFC action potential could elicit an autaptic current with similar slow kinetics to the postsynaptic response. The autapses reported here showed close synaptic-like appositions that had no clear postsynaptic density opposed to the vesicle-filled boutons of the same cell. This unusual bouton arrangement was recently shown (Oláh et al., 2009) to mediate release of GABA into the extracellular space, which is broad in volume and mediates tonic GABAergic conductance onto nearby cells through activation of extrasynaptic $\delta$-containing receptors. In the same study, it was also shown that it has an impact on glutamate release from nearby excitatory terminals expressing $\mathrm{GABA}_{\mathrm{B}}$ receptors as has also been shown for their own release of GABA in an autocrine way (Price et al., 2005). What is, however, the temporal profile of the GABA concentration released by NGFCs? 
We estimated that concentrations of GABA in the micromolar range must remain in the cleft for several milliseconds at NGFC synapses by using competitive antagonists for $\mathrm{GABA}_{\mathrm{A}}$ receptors (Overstreet et al., 2002) and kinetic receptor modeling. This is at odds with previous quantitative estimates of synaptic GABA transients not exceeding $0.5 \mathrm{~ms}$ (Overstreet et al., 2002; Mozrzymas et al., 2003). Likewise, glycine, another inhibitory neurotransmitter of the CNS, reaches a peak concentration of $2.2-3.5 \mathrm{~mm}$ and is cleared from the synaptic cleft with a time constant of $0.6-0.9 \mathrm{~ms}$ (Beato, 2008). The GABA released by NGFCs is likely to activate the classical synaptic $\alpha 1 \beta 2 / 3 \gamma 2 \mathrm{GABA}_{\mathrm{A}}$ receptor, but also highaffinity receptors containing the $\alpha 5$ subunit, in agreement with a previous study (Szabadics et al., 2007), and $\delta$-containing $\mathrm{GABA}_{\mathrm{A}}$ receptors (Szabadics et al., 2007; Oláh et al., 2009). We recently observed diffuse immunostaining of the $\alpha 1$ subunit on NGFC dendrites (Fuentealba et al., 2010), providing a substrate for the activation of both synaptic and extrasynaptic $\alpha 1 \gamma 2$ and/or $\alpha 1 \alpha 5 \gamma 2$-containing or even $\alpha 1 \delta \mathrm{GABA}_{\mathrm{A}}$ receptors by spillover of GABA (Glykys et al., 2007; Oláh et al., 2009). Nevertheless, the latter combination would render the receptors insensitive to zolpidem or diazepam and the presence of the $\alpha 5$ subunit confers fast deactivation (Picton and Fisher, 2007). Thus, receptor subunit specificity is unlikely to account for the NGFC response duration, consistent with a recent report in which slow inhibition from interneurons of the SLM in mice lacking the $\mathrm{GABA}_{\mathrm{A}}$ receptor $\beta 3$ subunit is intact (Hentschke et al., 2009). Conversely, the spatiotemporal and concentration profile of GABA appears to represent a crucial factor. It is noteworthy here that the slow unbinding rate of GABA was proposed to be responsible for the slow IPSCs detected in neurons of the thalamic reticular nucleus (Schofield and Huguenard, 2007).

The NGFC temporal GABA profile not only activates postsynaptic receptors but also leads to their desensitization, which in turn contributes to plastic depression. Single-channel recordings indicate that the $\mathrm{GABA}_{\mathrm{A}}$ receptor oscillates between open and long desensitized states (Jones and Westbrook, 1995). The shape of the IPSC can be broken down into rapid binding and channel opening (rising phase), followed by a burst of oscillations between bound and open states (fast decay phase), then by clusters of bursts separated by visits to desensitized states (slow decay phase) and eventual unbinding. Although no current flows through the channel while it is desensitized, visits to desensitized states prolong the total duration of channel activity after transient exposure to GABA. Our observation that zolpidem or diazepam increased IPSC amplitude but accelerated the decay is unusual (Szabadics et al., 2007) given that zolpidem is thought to speed GABA binding and slow unbinding, thus prolonging the decay of fast IPSCs (Perrais and Ropert, 1999). However, benzodiazepine agonists may also enhance receptor desensitization (Mellor and Randall, 1997; Mozrzymas et al., 2007). By incorporating enhanced desensitization into our kinetic model of the zolpidem effect, we found that the slow GABA transient allows multiple rounds of GABA rebinding to accentuate desensitization, reducing the ability of GABA to open the channels multiple times, hence reducing the IPSC duration.

It is typical that GABAergic synapses show a use-dependent depression (Jiang et al., 2000). This phenomenon is very strong in NGFCs: their synaptic response evoked by a single action potential is stable only when it is elicited every 1-2 min (Tamás et al., 2003; Price et al., 2005); stimulation at $5 \mathrm{~Hz}$ elicits a profound short-term depression tightly regulated by presynaptic $G_{A B} A_{B}$ receptors (Price et al., 2005, 2008). We show here that a train of action potentials at $0.1 \mathrm{~Hz}$ or higher frequency firing of NGFCs as observed during theta oscillations in vivo, strongly but reversibly decreases the IPSC amplitude in $\mathrm{GABA}_{\mathrm{B}}$ receptor-independent way. Elevation of ambient GABA by blocking the GAT-1 transporter or by applying exogenous GABA significantly enhanced the $0.1-\mathrm{Hz}$-induced depression, whereas TPMPA reduced it, since it counteracted the prolonged binding of GABA on the receptors and hence reduced their visits to desensitized states. Consistent with this, we observed a time course for recovery from paired-pulse depression in agreement with the recovery from desensitization of $\mathrm{GABA}_{\mathrm{A}}$ receptors in outside-out patches (Jones and Westbrook, 1995) and with recovery of IPSC amplitude after pre-desensitization with low concentrations of GABA (Overstreet et al., 2000). Our data rule out the involvement of presynaptic $\mathrm{Ca}^{2+}$ per se as a mediator of this depression, since $\mathrm{Ca}^{2+}$ transients at individual axonal boutons of NGFCs evoked by somatic action potentials did not decrement during stimulus trains that cause IPSC depression. Yet a contribution of presynaptic mechanisms to the midterm synaptic depression observed, such as depletion of the readily releasable pool of vesicles and slow refilling by the reserve pool of vesicles, cannot be ruled out.

Given the robust response depression after in vivo firing of NGFCs, it is important to hypothesize on the role of the transmitter released by this cell type, taking also into account that subpopulations of NGFCs may exist (Tricoire et al., 2010). Our study and another one recently published (Oláh et al., 2009) offer some clues. Even when GABA released by NGFCs does not have an impact on postsynaptic $\mathrm{GABA}_{\mathrm{A}}$ receptors because of desensitization, it will nevertheless have an impact on extrasynaptically located $\delta$-containing receptors (Oláh et al., 2009), which are in fact resistant to desensitization (Glykys et al., 2007). In addition, it will also activate $\mathrm{GABA}_{\mathrm{B}}$ receptors located on perisynaptic sites of dendrites but also presynaptically onto NGFCs (Tamás et al., 2003; Price et al., 2005) and pyramidal cell terminals (Oláh et al., 2009), each of which will have cellular and network effects (PérezGarci et al., 2006; Oswald et al., 2009). Hence NGFCs are in a unique position to act as cellular switches between local and global effects on cell dynamics having a unique modular and adaptive role shared by no other interneuron known to date.

\section{References}

Ali AB, Thomson AM (2008) Synaptic alpha 5 subunit-containing GABA $_{\mathrm{A}}$ receptors mediate IPSPs elicited by dendrite-preferring cells in rat neocortex. Cereb Cortex 18:1260-1271.

Bacci A, Huguenard JR (2006) Enhancement of spike-timing precision by autaptic transmission in neocortical inhibitory interneurons. Neuron 49:119-130.

Banks MI, Li TB, Pearce RA (1998) The synaptic basis of GABA A,slow $_{\text {. }}$ J Neurosci 18:1305-1317.

Banks MI, White JA, Pearce RA (2000) Interactions between distinct $\mathrm{GABA}_{\mathrm{A}}$ circuits in hippocampus. Neuron 25:449-457.

Bartos M, Vida I, Frotscher M, Geiger JR, Jonas P (2001) Rapid signaling at inhibitory synapses in a dentate gyrus interneuron network. J Neurosci 21:2687-2698.

Beato M (2008) The time course of transmitter at glycinergic synapses onto motoneurons. J Neurosci 28:7412-7425.

Caraiscos VB, Elliott EM, You-Ten KE, Cheng VY, Belelli D, Newell JG, Jackson MF, Lambert JJ, Rosahl TW, Wafford KA, MacDonald JF, Orser BA (2004) Tonic inhibition in mouse hippocampal CA1 pyramidal neurons is mediated by alpha5 subunit-containing gamma-aminobutyric acid type A receptors. Proc Natl Acad Sci U S A 101:3662-3667.

Colquhoun D, Hawkes AG (1995a) The principles of the stochastic interpretation of ion-channel mechanisms. In: Single-channel recording (Sakmann B, Neher E, eds), pp 397-482. New York: Plenum.

Colquhoun D, Hawkes AG (1995b) A Q-matrix cookbook. How to write only one program to calculate the single-channel and macroscopic predictions for any kinetic mechanism. In: Single-channel recording (Sakmann B, Neher E, eds), pp 589-633. New York: Plenum. 
Dvorak-Carbone H, Schuman EM (1999) Patterned activity in stratum lacunosum moleculare inhibits CA1 pyramidal neuron firing. J Neurophysiol 82:3213-3222.

Farrant M, Nusser Z (2005) Variations on an inhibitory theme: phasic and tonic activation of $\mathrm{GABA}_{\mathrm{A}}$ receptors. Nat Rev Neurosci 6:215-229.

Fuentealba P, Begum R, Capogna M, Jinno S, Márton LF, Csicsvari J, Thomson A, Somogyi P, Klausberger T (2008) Ivy cells: a population of nitric-oxideproducing, slow-spiking GABAergic neurons and their involvement in hippocampal network activity. Neuron 57:917-929.

Fuentealba P, Klausberger T, Karayannis T, Suen WY, Huck J, Tomioka R, Rockland K, Capogna M, Studer M, Morales M, Somogyi P (2010) Expression of COUP-TFII nuclear receptor in restricted GABAergic neuronal populations in the adult rat hippocampus. J Neurosci 30:1595-1609.

Glykys J, Peng Z, Chandra D, Homanics GE, Houser CR, Mody I (2007) A new naturally occurring $\mathrm{GABA}_{\mathrm{A}}$ receptor subunit partnership with high sensitivity to ethanol. Nat Neurosci 10:40-48.

Gupta A, Wang Y, Markram H (2000) Organizing principles for a diversity of GABAergic interneurons and synapses in the neocortex. Science 287:273-278.

Hájos N, Mody I (1997) Synaptic communication among hippocampal interneurons: properties of spontaneous IPSCs in morphologically identified cells. J Neurosci 17:8427-8442.

Hentschke H, Benkwitz C, Banks MI, Perkins MG, Homanics GE, Pearce RA (2009) Altered $\mathrm{GABA}_{\mathrm{A}, \text { slow }}$ inhibition and network oscillations in mice lacking the $\mathrm{GABA}_{\mathrm{A}}$ receptor $\beta 3$ subunit. J Neurophysiol 102:3643-3655.

Jiang L, Sun S, Nedergaard M, Kang J (2000) Paired-pulse modulation at individual GABAergic synapses in rat hippocampus. J Physiol 523:425-439.

Jones MV, Westbrook GL (1995) Desensitized states prolong $\mathrm{GABA}_{\mathrm{A}}$ channel responses to brief agonist pulses. Neuron 15:181-191.

Jones MV, Sahara Y, Dzubay JA, Westbrook GL (1998) Defining affinity with the $\mathrm{GABA}_{\mathrm{A}}$ receptor. J Neurosci 18:8590-8604.

Jones MV, Jonas P, Sahara Y, Westbrook GL (2001) Microscopic kinetics and energetics distinguish $\mathrm{GABA}_{\mathrm{A}}$ receptor agonists from antagonists. Biophys J 81:2660-2670.

Maccaferri G, Roberts JD, Szucs P, Cottingham CA, Somogyi P (2000) Cell surface domain specific postsynaptic currents evoked by identified GABAergic neurones in rat hippocampus in vitro. J Physiol 524:91-116.

Mellor JR, Randall AD (1997) Frequency-dependent actions of benzodiazepines on $\mathrm{GABA}_{\mathrm{A}}$ receptors in cultured murine cerebellar granule cells. J Physiol 503:353-369.

Molnár G, Oláh S, Komlósi G, Füle M, Szabadics J, Varga C, Barzó P, Tamás G (2008) Complex events initiated by individual spikes in the human cerebral cortex. PLoS Biol 6:e222.

Mozrzymas JW, Zarnowska ED, Pytel M, Mercik K, Zarmowska ED (2003) Modulation of $\mathrm{GABA}_{\mathrm{A}}$ receptors by hydrogen ions reveals synaptic GABA transient and a crucial role of the desensitization process. J Neurosci 23:7981-7992.

Mozrzymas JW, Wójtowicz T, Piast M, Lebida K, Wyrembek P, Mercik K (2007) GABA transient sets the susceptibility of mIPSCs to modulation by benzodiazepine receptor agonists in rat hippocampal neurons. J Physiol 585:29-46.

Nelder A, Mead R (1965) A simplex method for function minimization. Comput J 7:308-313.

Oláh S, Komlósi G, Szabadics J, Varga C, Tóth E, Barzó P, Tamás G (2007) Output of neurogliaform cells to various neuron types in the human and rat cerebral cortex. Front Neural Circuits 1:4.

Oláh S, Füle M, Komlósi G, Varga C, Báldi R, Barzó P, Tamás G (2009) Regulation of cortical microcircuits by unitary GABA-mediated volume transmission. Nature 461:1278-1281.

Oswald AM, Doiron B, Rinzel J, Reyes AD (2009) Spatial profile and differential recruitment of $\mathrm{GABA}_{\mathrm{B}}$ modulate oscillatory activity in auditory cortex. J Neurosci 29:10321-10334.

Ouardouz M, Lacaille JC (1997) Properties of unitary IPSCs in hippocampal pyramidal cells originating from different types of interneurons in young rats. J Neurophysiol 77:1939-1949.

Overstreet LS, Westbrook GL (2003) Synapse density regulates independence at unitary inhibitory synapses. J Neurosci 23:2618-2626.

Overstreet LS, Jones MV, Westbrook GL (2000) Slow desensitization regulates

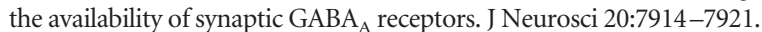

Overstreet LS, Westbrook GL, Jones MV (2002) Measuring and modeling the spatiotemporal profile of GABA at the synapse. In: Transmembrane transporters (Quick M, ed), pp 259-275. New York: Wiley.

Pawelzik H, Hughes DI, Thomson AM (2003) Modulation of inhibitory autapses and synapses on rat CA1 interneurones by $\mathrm{GABA}_{\mathrm{A}}$ receptor ligands. J Physiol 546:701-716.

Pearce RA (1993) Physiological evidence for two distinct $\mathrm{GABA}_{\mathrm{A}}$ responses in rat hippocampus. Neuron 10:189-200.

Pérez-Garci E, Gassmann M, Bettler B, Larkum ME (2006) The GABAB1b isoform mediates long-lasting inhibition of dendritic $\mathrm{Ca}^{2+}$ spikes in layer 5 somatosensory pyramidal neurons. Neuron 50:603-616.

Perrais D, Ropert N (1999) Effect of zolpidem on miniature IPSCs and occupancy of postsynaptic $\mathrm{GABA}_{\mathrm{A}}$ receptors in central synapses. J Neurosci 19:578-588.

Picton AJ, Fisher JL (2007) Effect of the alpha subunit subtype on the macroscopic kinetic properties of recombinant $\mathrm{GABA}_{\mathrm{A}}$ receptors. Brain Res 1165:40-49.

Prenosil GA, Schneider Gasser EM, Rudolph U, Keist R, Fritschy JM, Vogt KE (2006) Specific subtypes of $\mathrm{GABA}_{\mathrm{A}}$ receptors mediate phasic and tonic forms of inhibition in hippocampal pyramidal neurons. J Neurophysiol 96:846-857.

Price CJ, Cauli B, Kovacs ER, Kulik A, Lambolez B, Shigemoto R, Capogna M (2005) Neurogliaform neurons form a novel inhibitory network in the hippocampal CA1 area. J Neurosci 25:6775-6786.

Price CJ, Scott R, Rusakov DA, Capogna M (2008) GABA $\mathrm{B}_{\mathrm{B}}$ receptor modulation of feedforward inhibition through hippocampal neurogliaform cells. J Neurosci 28:6974-6982.

Rizzoli SO, Betz WJ (2005) Synaptic vesicle pools. Nat Rev Neurosci $6: 57-69$.

Rusakov DA, Wuerz A, Kullmann DM (2004) Heterogeneity and specificity of presynaptic $\mathrm{Ca}^{2+}$ current modulation by mGluRs at individual hippocampal synapses. Cereb Cortex 14:748-758.

Schofield CM, Huguenard JR (2007) GABA affinity shapes IPSCs in thalamic nuclei. J Neurosci 27:7954-7962.

Scimemi A, Fine A, Kullmann DM, Rusakov DA (2004) NR2B-containing receptors mediate cross talk among hippocampal synapses. J Neurosci 24:4767-4777

Scott R, Rusakov DA (2006) Main determinants of presynaptic $\mathrm{Ca}^{2+} \mathrm{dy}-$ namics at individual mossy fiber-CA3 pyramidal cell synapses. J Neurosci 26:7071-7081.

Szabadics J, Tamás G, Soltesz I (2007) Different transmitter transients underlie presynaptic cell type specificity of $\mathrm{GABA}_{\mathrm{A} \text {,slow }}$ and $\mathrm{GABA}_{\mathrm{A} \text {,fast }}$. Proc Natl Acad Sci U S A 104:14831-14836.

Tamás G, Lorincz A, Simon A, Szabadics J (2003) Identified sources and targets of slow inhibition in the neocortex. Science 299:1902-1905.

Tricoire L, Pelkey KA, Daw MI, Sousa VH, Miyoshi G, Jeffries B, Cauli B, Fishell G, McBain CJ (2010) Common origins of hippocampal ivy and nitric oxide synthase expressing neurogliaform cells. J Neurosci 30:2165-2176.

Whiting PJ, McAllister G, Vassilatis D, Bonnert TP, Heavens RP, Smith DW, Hewson L, O’Donnell R, Rigby MR, Sirinathsinghji DJ, Marshall G, Thompson SA, Wafford KA, Vasilatis D (1997) Neuronally restricted RNA splicing regulates the expression of a novel $\mathrm{GABA}_{\mathrm{A}}$ receptor subunit conferring atypical functional properties. J Neurosci 17:5027-5037.

Wieland HA, Lüddens H, Seeburg PH (1992) Molecular determinants in GABAA/BZ receptor subtypes. Adv Biochem Psychopharmacol 47:29-40.

Zucker RS, Regehr WG (2002) Short-term synaptic plasticity. Annu Rev Physiol 64:355-405. 